\title{
Anti-parasitic activity of polyether ionophores
}

\author{
Michał Antoszczak ${ }^{a}$, Dietmar Steverding ${ }^{\mathrm{b}}$, Adam Huczyński a, \\ ${ }^{a}$ Department of Bioorganic Chemistry, Faculty of Chemistry, Adam Mickiewicz University, \\ Umultowska 89b, 61-614 Poznań, Poland \\ ${ }^{b}$ Bob Champion Research \& Education Building, Norwich Medical School, University of East \\ Anglia, Norwich, UK
}

\begin{abstract}
Despite some progress in recent years, the fight against parasitic diseases still remains a great challenge. Parasitic diseases affect primarily (but not exclusively) the poorest people living in underdeveloped regions of the world. The distribution of parasitoses are linked to tropical and subtropical climate conditions, to population growth and to impoverishment. If not treated, parasitic diseases may lead to serious health problems, and even death. Particularly vulnerable groups include infants and young children, pregnant women and immunocompromised individuals. Polyether ionophore antibiotics (ionophores), traditionally used in veterinary medicine as anti-coccidial feed additives and non-hormonal growth promoters, are of considerable interest, as they have been found to be highly effective agents against various parasites, both in vitro and in vivo. This review summarizes the anti-parasitic effects of the most important polyether ionophores against parasites that are responsible for a number of animal and human parasitic diseases. Recent findings and advances that support the potential of polyether ionophore antibiotics as novel anti-parasitic drug candidates are also presented and discussed.
\end{abstract}

Keywords: Ionophores; lasalocid acid; monensin; salinomycin; parasites; parasitic diseases

Corresponding author: E-mail: adhucz@amu.edu.pl (A. Huczyński) 


\section{Introduction}

Although parasites have accompanied mankind since the dawn of history [1], parasitic diseases are becoming an increasing human life and health concern, especially in the developing world [2-5]. Globally, parasitic diseases are responsible for almost one million deaths every year [6] which is nearly the same mortality rate caused by HIV/AIDS [7]. Infectious and parasitic diseases remain the major killers of children in low-income nations [8-10]. According to the World Health Organization (WHO), malaria, as the major parasitic disease killer, caused about 445,000 deaths in 2016, with many of those being in African children under the age of five [11]; it is however believed that many cases are undiagnosed and therefore unreported.

Parasites are distributed on all continents, but some latitudes are disproportionately more affected than others [12]. In tropical, subtropical and temperate regions, the combination of warm and humid climate with significant population growth and the accompanying poverty, contribute to the increased transmission of parasitic infections $[3,5,12,13]$, most often by vectors such as mosquitos or ticks. Some parasites, like protozoans belonging to the Plasmodium group that are responsible for malaria, are a common cause of deaths worldwide $[8,9]$, while others may lead to blindness, devastating neurological deficits, disfigurement and severe other disabilities and economic hardships [14-16]. Interestingly, among the 10 globally important tropical diseases, seven are parasitic ones, including African and American trypanosomiasis (sleeping sickness and Chagas disease, respectively), leishmaniasis, lymphatic filariasis, malaria, onchocerciasis and schistosomiasis [3].

Although parasitic diseases constitute a serious health problem for millions of people, especially in Africa, Latin America and Asia, many of the most common parasitic diseases are classified as neglected tropical diseases [17,18], and are comparatively less studied than other infectious diseases prevalent in high-income nations. In developed countries, protozoan 
parasites more commonly cause gastrointestinal infections $[12,19,20]$ than constitute the source of life-threatening infections, and for this reason, they raise relatively little interest in the scientific community. However, anybody who travels to endemic areas is at risk of contracting a parasitic disease and bringing it back home; such cases are known as "imported parasitic diseases" [21-23], and they represent a major obstacle in the effective elimination of several parasitoses.

Another problem is that currently used anti-parasitic drugs have a number of limitations; they are difficult to administer, toxic, expensive and predominantly limited in scope, efficacy and/or availability [24-26]. Moreover, the phenomenon of drug resistance is spreading rapidly and many promising vaccines have not met expectations [27-29]. Therefore, there is an important need to focus on the discovery of novel, more effective and safer agents to control parasitic diseases. In this article, we show that polyether ionophore antibiotics (ionophores) and their derivatives are highly biologically active compounds, which should be considered as potential candidates for the development of new anti-parasitic chemotherapeutics.

\section{Structure of polyether ionophores}

Polyether ionophore antibiotics (Figure 1) are a group of more than 120 structurally characterized lipid-soluble compounds that consist of similar building blocks, share a common mode of action, and are produced by Gram $(+)$ bacteria of the genus Streptomyces [30,31]. Functionally, the high anti-microbial bioactivity of ionophores (i.e. ion carriers) is strictly connected with their ionophoric properties. They have the ability to selectively bind metal cations, mainly alkali ones, and transport them from extracellular environment through biological membranes into cells [32-34], where the transported cation is released. As a result, the whole process disturbs the natural sodium/potassium concentration gradient (ion balance). 
This leads to changes in the intracellular $\mathrm{pH}$, to an increase in osmotic pressure, to formation of vacuoles within the cells (vacuolization), to mitochondrial injuries, to cell swelling by subsequent entry of water, and finally may result in cell death [35].

Monovalent polyether ionophores
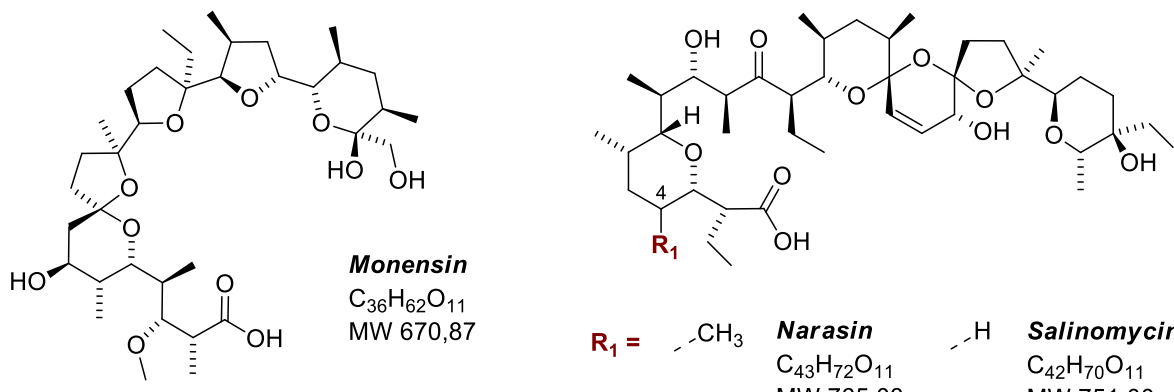

$$
\mathbf{R}_{1}=,-\mathrm{CH}_{3} \begin{aligned}
& \text { Narasin } \\
& \mathrm{C}_{43} \mathrm{H}_{72} \mathrm{O}_{11} \\
& \mathrm{MW} \mathrm{765,03}
\end{aligned},-\mathrm{H} \quad \begin{aligned}
& \text { Salinomycin } \\
& \mathrm{C}_{42} \mathrm{H}_{70} \mathrm{O}_{11} \\
&
\end{aligned}
$$

Monovalent glycoside polyether ionophores
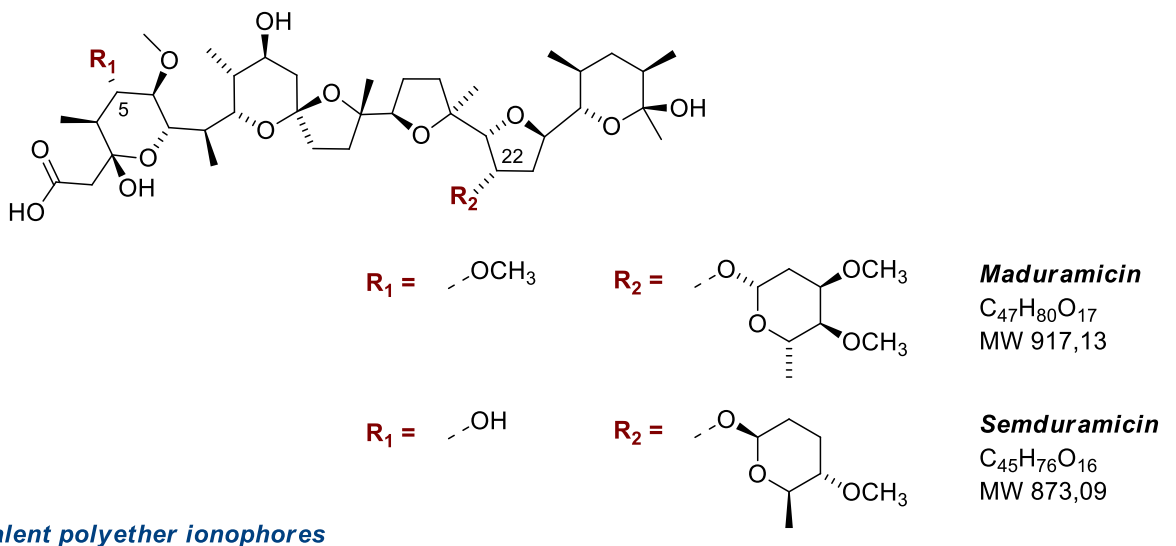

Divalent polyether ionophores $\mathrm{C}_{45} \mathrm{H}_{76} \mathrm{O}_{16}$
$\mathrm{MW} 873,09$

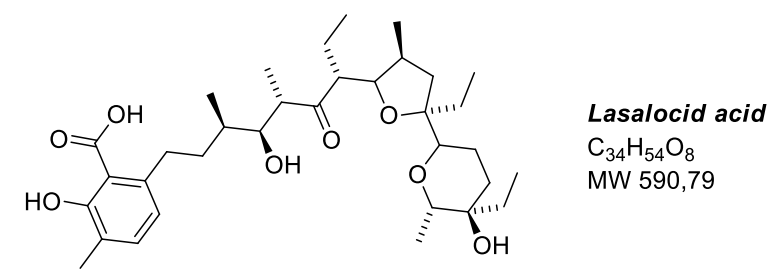

Figure 1. Structure of the most commonly used anti-coccidial polyether ionophore drugs that are incorporated in cattle and poultry feeds.

Importantly, all ionophore antibiotics have common structural motifs (Figure 1). Their inner part is a hydrophilic polar cavity (pocket), which is formed not only by the ether oxygen atoms (usually as elements of tetrahydrofuran and/or tetrahydropyran rings), but also by the 
oxygen atoms that belong to other functionally important groups, such as ketone and/or hydroxyl $[35,36]$.

The cation-binding selectivity (affinity) of ionophores is connected with their structure and the size of the polar pocket, inside which only the cations with strictly defined radii may be bound (Figure 2 and Table 1) [37-46]. Polyether ionophores may be classified as monoor divalent ones if they are able to transport only monovalent cations or if besides monovalent cations, they have also the ability to transport divalent cations [47]. For example, lasalocid acid is recognized as a divalent ionophore as it shows a similar affinity for $\mathrm{Cs}^{+}$and $\mathrm{Ba}^{2+}$ cations, while monensin is known as monovalent ionophore antibiotic because of its high affinity to $\mathrm{Na}^{+}$cations (Figure 2 and Table 1) [41-46].
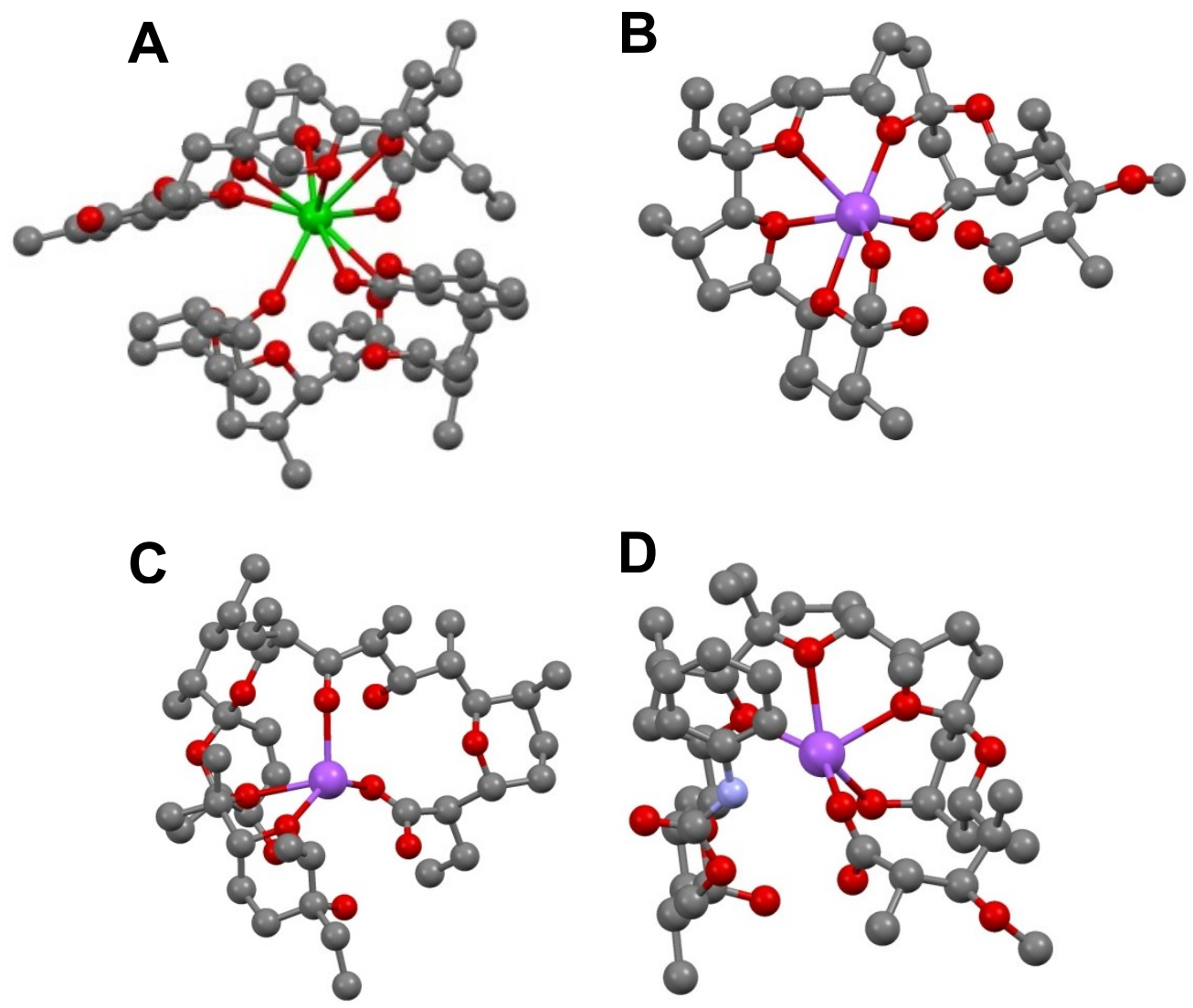

Figure 2. Structure of complexes of (A) lasalocid acid dimer with $\mathrm{Ba}^{2+}$, (B) monensin with $\mathrm{Na}^{+}$, (C) salinomycin with $\mathrm{Na}^{+}$and (D) C(26) phenyl carbamate of monensin sodium salt (compound 8, Figure 5), which was determined using single-crystal X-ray diffraction method [37-40]. The hydrogen atoms and solvent molecules are omitted for clarity. 
Table 1. Selectivity of complexation of metal cations by polyether ionophores [41-46].

\begin{tabular}{|c|c|}
\hline $\begin{array}{l}\text { Polyether } \\
\text { ionophore }\end{array}$ & $\begin{array}{l}\text { Selectivity of complexation of metal } \\
\text { cations }\end{array}$ \\
\hline Ionomycin & $\mathrm{Ca}^{2+}>\mathrm{Mg}^{2+}>>\mathrm{Sr}^{2+} \approx \mathrm{Ba}^{2+}$ \\
\hline \multirow{2}{*}{ Lasalocid acid } & $\mathrm{Cs}^{+}>\mathrm{Rb}^{+} \approx \mathrm{K}^{+}>\mathrm{Na}^{+}>\mathrm{Li}^{+}$ \\
\hline & $\mathrm{Ba}^{2+}>\mathrm{Sr}^{2+}>\mathrm{Ca}^{2+}>\mathrm{Mg}^{2+}$ \\
\hline Monensin & $\mathrm{Na}^{+}>\mathrm{K}^{+}>\mathrm{Rb}^{+}>\mathrm{Cs}^{+}>\mathrm{Li}^{+}$ \\
\hline Salinomycin & $\mathrm{K}^{+}>\mathrm{Na}^{+}>\mathrm{Cs}^{+}>\mathrm{Sr}^{2+}>\mathrm{Ca}^{2+} \approx \mathrm{Mg}^{2+}$ \\
\hline Valinomycin & $\mathrm{Rb}^{+}>\mathrm{K}^{+}>\mathrm{Cs}^{+}>\mathrm{Ag}^{+}>\mathrm{Na}^{+}>\mathrm{Li}^{+}$ \\
\hline
\end{tabular}

On the other hand, the outer part of ionophore antibiotic molecules comprises hydrophobic hydrocarbon skeletons with many methyl, ethyl and other non-polar groups (Figure 1). The presence of a hydrophobic surface guarantees high lipophilicity of the whole ionophore molecule, and thus facilitates its diffusion through cell membranes from the extracellular environment into target cells $[35,36]$.

Among the numerous polyether ionophore antibiotics reported to date, there is a subgroup of nearly hundred compounds that act as freely mobile carriers across biological membranes. These biomolecules have been described as carboxylic ionophores, also known as nigericin antibiotics, in whose structure an additional terminal carboxyl group is present (Figure 1) that takes active part in the cation complexing process (Figure 2). Moreover, because of the presence of a carboxyl group at one end of the molecule and a hydroxyl group(s) at the other end, there is the possibility of the formation of a non-covalent link between both ends by intramolecular "head-to-tail" hydrogen bond(s), leading to a stable pseudocyclic conformation. Within such pseudocyclic structure, the selectively bound cation is completely enclosed in the polar cavity and shielded from the external environment (Figure 2). Consequently, the bound cation can be effectively transferred into the interior of cells $[48,49]$. 


\section{Carboxylic ionophores - mechanism of cation transport}

Knowledge of the mechanism of cation transport realized by carboxylic ionophores is essential for both full understanding of the functioning of this subgroup of natural compounds and for explaining the broad spectrum of their biological properties. Mechanistically, carboxylic polyether ionophores transport cations in the form of host-guest complexes (Figure 2) through biological membranes in accordance with the one of the three different mechanisms described in literature (Figure 3) [48,49]. The particular mechanism depends on the cellular environment and the chemical structure of the ionophore. The transport can be realized (i) in the form of a neutral ionophore-cation complex (electroneutral transport mechanism), (ii) in the form of positively charged ionophore-cation complex, in which the carboxyl group of the ionophore is not chemically modified (electrogenic transport mechanism), or (iii) in the form of positively charged ionophore-cation complex, in which the carboxyl group of ionophore is chemically modified, for example, in the case of amide/ester analogues (bio-mimetic transport mechanism) (Figure 3) [48,49].

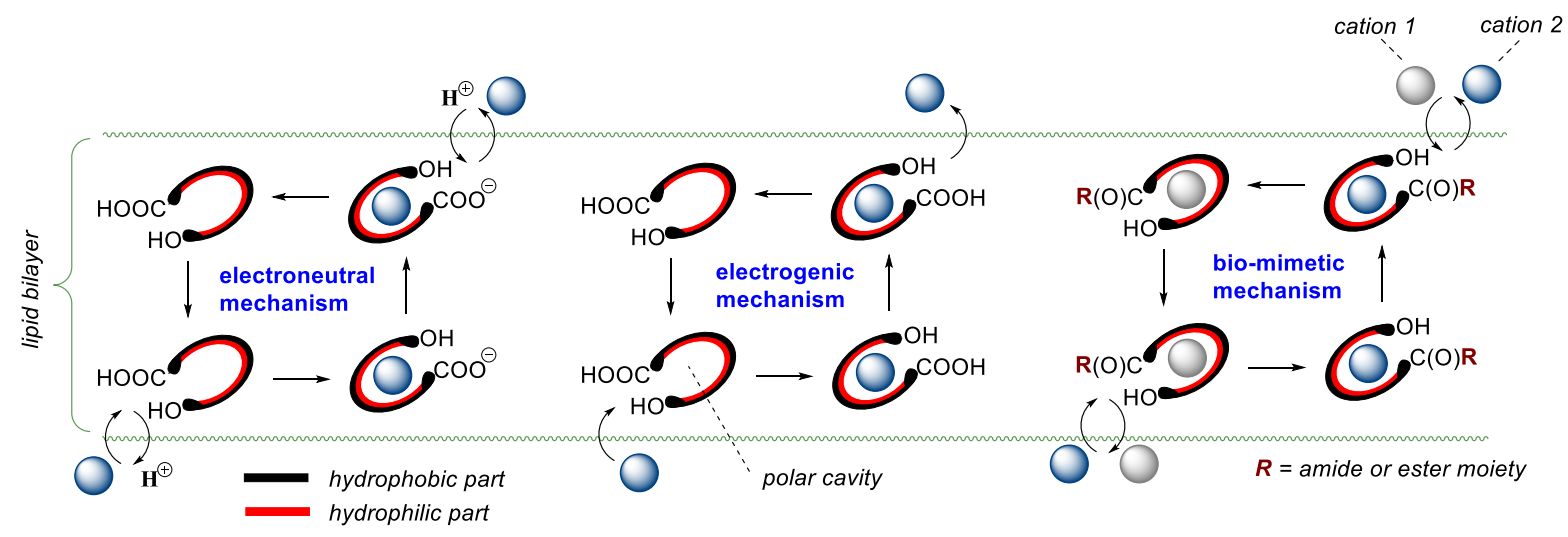

Figure 3. Mechanisms of cations transport through biological membranes mediated by carboxylic polyether ionophores $[48,49]$.

The bio-mimetic transport mechanism, being a type of electrogenic transport mode, involves the exchange of the metal cations of a pseudocyclic complex. Such complex is 
formed between chemically modified polyether ionophore and guest cation at the one side of the lipid bilayer, and then diffuses across the biological membrane. At the opposite side, a cation-exchange process with counter-transported cation releases the guest cation. As a result, guest and counter-transported cations are transported through the lipid membrane in opposite directions (Figure 3) [48,49].

Since the driving force of the bio-mimetic transport mechanism is the concentration gradient of the counter-transported cations, a $\mathrm{pH}$ gradient is not required. Thus, it should be pointed out that the electroneutral transport is carried under neutral (inert) or basic conditions, because only under such conditions the carboxyl group of ionophore may undergo deprotonation $[48,49]$. On the other hand, electrogenic or bio-mimetic transport mechanism may be efficiently realized under non-basic conditions [48,49].

As a group of highly biologically active compounds, polyether ionophores show a broad spectrum of interesting pharmacological properties [35,50,51]. Some of these compounds have been used in veterinary medicine as non-hormonal growth promoters in ruminants because of their potent activity against various $\operatorname{Gram}(+)$ bacteria, and as agents to control the parasitic disease coccidiosis [35,51]. In addition, polyether ionophores have been shown to display activity against various human cancer cell lines and xenograft tumours. Moreover, anti-cancer activity of polyether ionophores have been demonstrated in a small group of cancer patients. They also have been shown to exhibit activity against multi-drug resistant cancer cells and cancer stem cells of different origin [52-54]. Importantly, in addition to the industrial use of ionophores in animal husbandry [55], some of them show anti-fungal, anti-viral, and anti-parasitic activity [35,51].

\section{Polyether ionophores - promising anti-parasitic drug candidates}


Accumulating evidences clearly indicate that selected polyether ionophores and their semi-synthetic derivatives should be considered as potential agents in the development of effective drugs for the treatment of parasitic diseases [35,51]. For example, their effectiveness against parasites responsible for cryptosporidiosis, malaria, babesiosis, leishmaniasis, sarcocystosis and toxoplasmosis have been well documented in the scientific literature and will be presented in this review article. To the best of our knowledge, there is however no comprehensive review article in the scientific literature that would summarize the latest findings regarding the anti-parasitic activity of ionophores. Until now, the structures of more than one hundred polyether antibiotics have been determined, but only six carboxylic ionophores - lasalocid acid, maduramicin, monensin, narasin, salinomycin and semduramicin (Figure 1) - have been approved for use in veterinary practice (Table 2) [55].

Table 2. Ionophore-based anti-coccidial drugs used in cattle and poultry feeds [55].

\begin{tabular}{ll}
\hline Chemical name & Trade name \\
\hline Lasalocid acid & Avatec $^{\circledR}$, Bovatec $^{\circledR}$ \\
Maduramicin & $\operatorname{Cygro}^{\circledR}$ \\
Monensin & $\operatorname{Coban}^{\circledR}, \operatorname{Coxidin}^{\circledR}$, Elancoban $^{\circledR}$, Rumensin $^{\circledR}$ \\
Narasin & $\operatorname{Maxiban}^{\circledR}, \operatorname{Monteban}^{\circledR}$ \\
Salinomycin & $\operatorname{Biocox}^{\circledR}, \operatorname{Sacox}^{\circledR}, \operatorname{Salinomax}^{\circledR}$ \\
Semduramicin & $\operatorname{Aviax}^{\circledR}$ \\
\hline
\end{tabular}

Hence, in this review article the current status, recent progress and detailed discussion on the activity of the most promising carboxylic ionophores in the context of their potential use as novel and effective anti-parasitic agents are presented.

\subsection{Kinetoplastid diseases}

Kinetoplastids are a group of flagellated protozoans that are distinguished by the presence of a DNA-containing region, known as a "kinetoplast", in their single large 
mitochondrion. Sleeping sickness (caused by human pathogenic subspecies of Trypanosoma brucei), Chagas disease (caused by Trypanosoma cruzi) and the leishmaniases (caused by Leishmania spp.) are the major human diseases caused by kinetoplastids.

\subsubsection{African trypanosomiasis}

African trypanosomiasis, also known as sleeping sickness in humans or nagana disease in livestock animals, is a parasitic disease, which is caused by protozoans of the genus Trypanosoma [56-58]. The parasites are transmitted to humans and animals by the bites of the tsetse flies (Glossina spp.), which are only found in sub-Saharan Africa [59,60]. Historically, African trypanosomiasis was a serious economic and public health problem, causing several epidemics in Africa over the last century [61]. According to the WHO, the estimated number of actual cases is below 20,000, but the estimated population at risk is still about 65 million people [62].

Depending on the species involved, the clinical signs in the first (haemo-lymphatic) stage may include intermittent fever, headache, joint and muscle pains, malaise, rash, weight loss and enlarged lymph nodes in the first few weeks to months of the infection $[60,63]$. Thereafter, the trypanosomes cross the blood-brain barrier and invade the central nervous system, causing mental deterioration, personality changes, partial paralysis and other neurological problems $[60,63]$. The characteristic feature of the infection that gave the disease its name, is daytime sleepiness with night-time sleep disturbance (night-time insomnia) that results in progressive confusion [64]. Unfortunately, if not efficiently treated, African trypanosomiasis may finally lead to death after few months or years $[60,63]$.

As the few commonly used and outdated drugs available to treat sleeping sickness patients have limited efficacy as well as adverse side reactions, novel and better tolerated therapeutic strategies are highly desirable. The results from very recently published studies 
have clearly shown that three carboxylic polyether ionophores - lasalocid acid, monensin and salinomycin (Figure 1) - are interesting lead compounds for rational anti-trypanosomal drug development in this context [65-67]. Importantly, it has been shown that monensin and salinomycin inhibit the growth of culture-adapted bloodstream forms of T. brucei (clone 427 221a) in vitro at sub-micromolar concentration [66,67]. Although both ionophores have been shown to be less toxic to human cells (human myeloid leukemia HL-60 cells), their selectivity (cytotoxic to trypanocidal activity ratio) was only in a moderate range (GI $5_{50}$ ratio of 51 and 2.4 for monensin and salinomycin, respectively, where $\mathrm{GI}_{50}$ ratios have been calculated using the formula $\left.\mathrm{GI}_{50(\mathrm{HL}-60)} / \mathrm{GI}_{50(\text { T. brucei })}\right)[66]$.

Mechanistically, the trypanocidal mode of action of ionophore antibiotics has been shown to be the result of an influx of $\mathrm{Na}^{+}$resulting in an increased intracellular $\mathrm{Na}^{+}$ concentration followed by cell swelling (sodium influx-induced cell swelling) [67]. This mode of action differs from the mechanism of the anti-cancer activity of salinomycin reported to be the induction of apoptosis [53]. Interestingly, lasalocid acid has been found to induce a much faster cell swelling in trypanosomes than salinomycin and other polyether ionophores, and that the swelling was solely due to the influx of $\mathrm{Na}^{+}$cations [65]. Thus, it has been suggested that lasalocid acid may be directly applicable for the treatment of nagana disease, particularly as it is used in cattle as medicated feed additive (Table 2) [65].

An attractive approach to improve the activity of lead compounds is their chemical modification as the resulting derivatives may show better biological activity. In the case of salinomycin and monensin, most of the tested derivatives were less active against trypanosomes than their corresponding parent compounds [66].

However, two salinomycin derivatives (Figure 4, compounds 1-2) obtained by chemical modification of its carboxyl group have been identified to display increased trypanocidal activity, with $\mathrm{GI}_{50}$ values in the mid nanomolar range and MIC values of $<1$ 
$\mu \mathrm{M}$. The obtained anti-trypanosomal activity is similar to those of suramin, one of the drugs used in the treatment of sleeping sickness [66]. Both these salinomycin derivatives (Figure 4, compounds 1-2) have enhanced selectivity ( $\mathrm{GI}_{50}$ ratio of 288 and 363 for $\mathbf{1}$ and $\mathbf{2}$, respectively), proving undoubtedly the huge therapeutic potential of such analogues [66]. On the other hand, none Mannich base derivatives of lasalocid acid displayed better trypanocidal activity and selectivity than the unmodified lasalocid acid [65].
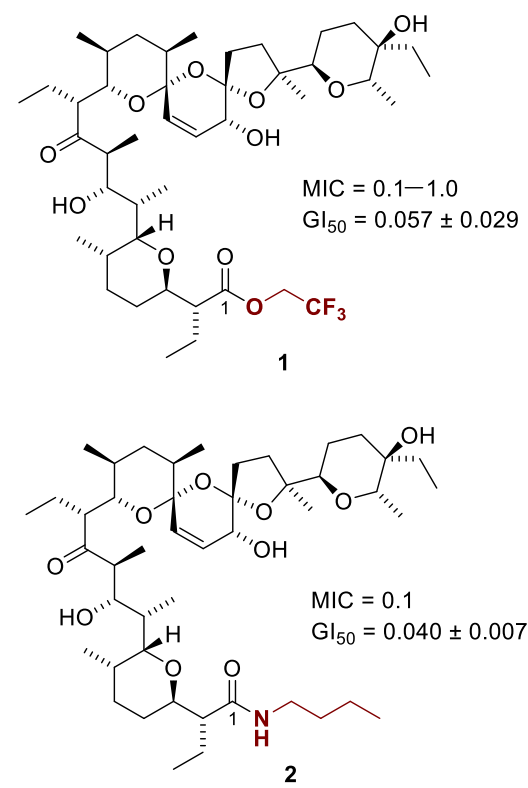

Figure 4. Structure of salinomycin derivatives with potent anti-trypanosomal activity against bloodstream forms of T. brucei (clone 427-221a) (MIC and GI 50 values in $\mu \mathrm{M}$ ) [66].

\subsubsection{Leishmaniasis}

Leishmaniasis is a vector-borne infection, which is caused by protozoans of the genus Leishmania [68,69]. The disease occurs worldwide in tropical and subtropical regions, and is transmitted to humans by the bite of infected female phlebotomine sandflies, mainly Phlebotomus and Lutzomyia [70]. There are about 20 different Leishmania species causing different forms of the diseases [71]. According to the WHO, between 700,000 to $1,000,000$ new cases of leishmaniasis occur annually and about 20,000 to 30,000 deaths, mainly in East Africa, South-East Asia and Latin America [72]. With respect to disease burden caused by 
tropical infections, leishmaniasis ranks second in mortality and fourth in morbidity [73]. The incidence of leishmaniasis is linked to environmental changes and several risk factors, including deforestation, irrigation schemes, malnutrition, socioeconomic conditions and urbanization [74].

Leishmaniasis causes a broad spectrum of clinical manifestations that strongly depend on the Leishmania species involved and the immune response of the host [75]. The symptoms of leishmaniasis are often skin sores (cutaneous and muco-cutaneous leishmaniasis) which erupt weeks to months after the infection, but also fever, low level of red blood cells as well as enlarged spleen and liver (visceral leishmaniasis) [76]. Moreover, co-infection with HIV may resulted in the developing of full-blown clinical disease, which is characterized by high rates of mortality [77].

Due to the different forms of leishmaniasis and the emergence of drug-resistant parasites, an efficient strategy of therapy of this disease remains a great challenge. Using both in vitro macrophage infection and ex vivo splenic explant models, monensin (Figure 1) was identified as one of the anti-leishmanial lead compounds against $L$. donovani with $\mathrm{EC}_{50}$ values of $0.23 \mu \mathrm{M}$ (in vitro tests) and $0.85 \mu \mathrm{M}$ (ex vivo tests) [78]. Because monensin demonstrated activity against L. donovani [78], the ionophore was also evaluated in vitro with L. major. Using the ex vivo lymph node system and macrophages infected with promastigotes of $L$. major, $\mathrm{EC}_{50}$ values for monensin were determined to be $0.09 \mu \mathrm{M}$ and $0.38 \mu \mathrm{M}$, respectively [79]. In addition, two other carboxylic polyether antibiotics, narasin and salinomycin differing only in one methyl group at the $\mathrm{C}(4)$ position (Figure 1), inhibited the proliferation of $L$. donovani promastigotes at micromolar concentrations [80]. However, both ionophores displayed lower leishmanicidal activity compared to monensin, with $\mathrm{EC}_{50}$ values of $2.0 \mu \mathrm{M}$ for narasin and $4.0 \mu \mathrm{M}$ for salinomycin [80]. Yet, the low therapeutic index of salinomycin for Leishmania species precluding its clinical use as a leishmanicidal agent $[80,81]$. 


\subsection{Apicomplexan diseases}

The Apicomplexa comprise a large phylum of obligate intracellular protozoan organisms that all have a parasitic lifestyle. This group is named after the apicopast, a vestigial plastid-like organelle present in most apicomplexans. The phylum Apicomplexa comprises over 5,000 species, many of which cause devastating diseases on a global scale. Human apicomplexan diseases include malaria, babesiosis, and toxoplasmosis, while coccidiosis is a common problem in livestock.

\subsubsection{Malaria}

Although great progress in the fight against malaria has been made since 2000, including significant reduction in mortality among children, it is still the most devastating parasitic disease globally, especially in sub-Saharan Africa [82]. In 2016, malaria infected 216 million people worldwide and caused about 445,000 deaths [83]. Another problem is the emergence of malaria parasites resistant against several currently used anti-malarial drugs, including chloroquine, which constitutes a serious health threat in poor regions of the world $[84,85]$. Fortunately, polyether ionophores represent a very promising class of compounds with potent anti-plasmodial activity in the nano- and picomolar concentration range $[81,86-$ 88].

Carboxylic ionophores, especially those that are specific to monovalent cations, have been reported as potent in vitro anti-malarial agents against various Plasmodium species [81,86-88], including $P$. berghei, $P$. falciparum, and $P$. yoelii, with $\mathrm{IC}_{50}$ values in the range of 0.6-6.5 $\mu \mathrm{g} \mathrm{ml}^{-1}[81,86,88]$. Similar degrees of effectiveness have been found in studies using animal models with $\mathrm{ED}_{50}$ values for in vivo anti-malarial activities varying between 0.4 and $4.1 \mathrm{mg} \mathrm{kg}^{-1}$ against $P$. chabaudi and $P$. petteri $[88,89]$. Using $P$. petteri, monensin (Figure 1) 
was identified as more effective anti-malarial agent in curing infected mice compared to nigericin $\left(\mathrm{ED}_{50}\right.$ and $\mathrm{ED}_{90}$ values for monensin and nigericin were 1.1 and $3.5 \mathrm{mg} \mathrm{kg}^{-1}$ and 1.8 and $4.6 \mathrm{mg} \mathrm{kg}^{-1}$, respectively) [87]. Importantly, polyether ionophores have been reported to be 30,000 -fold more potent in killing chloroquine-resistant malaria strains [51,87]. For example, $100 \%$ cure rates were obtained with monensin at doses of $10 \mathrm{mg} \mathrm{kg}^{-1}$ [87].

The drug target profile for malaria elimination/eradication policy proposed by the Medicines for Malaria Venture suggests to focus on molecules which are active against both asexual and sexual life-cycle stages of malaria parasites [90,91]. Although most commonly used anti-plasmodial agents are ineffective against $P$. falciparum gametocytes (the sexual stages of the parasites responsible for transmission to the Anopheles vector), the carboxylic ionophores maduramicin and narasin (Figure 1) have been found to display potent gametocytocidal activity in low nanomolar concentrations [92]. Furthermore, maduramicin was shown to block completely malaria transmission in an in vivo rodent malaria model. Moreover, in combination with the pyrazolemaide PA21A050 (another promising antimalarial drug candidate), the gametocytocidal activity of maduramicin was significantly potentiated [92]. Encouragingly, the monovalent carboxylic ionophores monensin, nigericin and salinomycin (Figure 1) have been shown to kill efficiently both P. falciparum asexual parasites and gametocytes with $\mathrm{IC}_{50}$ values in the nanomolar concentration range, and have been therefore identified as potent transmission-blocking agents [90].

Considering the increasing problem of drug-resistance in malaria parasites against the most commonly used anti-malarial drugs $[84,85]$, there is an urgent need to identify new molecules with potent anti-plasmodial activity. So far, a few studies on the action of ionophores towards both chloroquine-sensitive and chloroquine-resistant strains of $P$. falciparum had been carried out [86,93]. Some of the investigated polyether ionophores were shown to display anti-malarial activity against chloroquine-resistant strains with $\mathrm{IC}_{50}$ values 
of $0.15-6.4 \mathrm{nM}$, demonstrating the great potential of certain ionophores in overcoming drugresistance [86,93]. Interestingly, monensin and salinomycin were more potent against chloroquine-resistant strains than commonly used drugs, including amodiaquine, artemether, artemisinin, artesumate, pyrimethamanine, trimethoprim or quinine $[86,93]$. Of note is that the polyether ionophores showed even higher activity towards chloroquine-resistant strains than towards chloroquine-sensitive ones [86].

To improve the druggability and the therapeutic potential of polyether ionophores, development of various drug delivery systems that would be effective against drug-resistant strains of malaria parasites is a crucial need. In this context, a liposomal formulation loaded with the polyether antibiotic maduramicin was developed for the treatment of both chloroquine-sensitive and chloroquine-resistant Plasmodium infections. It was shown that liposome-based drug delivery of maduramicin enhanced its anti-malarial activity in vitro [94]. It was also found that delivery of monensin in PEGylated stearylamine liposomes increased the anti-malarial activity of the ionophore in vitro (liposomal monensin, $\mathrm{IC}_{50}=0.74 \mathrm{nM}$; free monensin, $\mathrm{IC}_{50}=3.17 \mathrm{nM}$ ) as well as in in vivo model systems without causing haemolysis of erythrocytes [95]. Importantly, liposomal monensin in combination with other anti-malarial drugs (e.g. chloroquine, FR900098 and piperaquine) showed additive to synergistic action towards $P$. falciparum and reduced the parasitic burden in $P$. berghei infected mice at comparable doses of anti-malarial drugs used alone [96]. Furthermore, it was found that monensin encapsulated in PLGA nanoparticles was about 10-fold more effective in impeding the growth of $P$. falciparum in culture compared to the free antibiotic [97].

To evaluate the anti-malarial therapeutic potential of ionophore antibiotics, the difference in the in vitro activity of the compounds between normal mammalian cells and malaria parasites (selectivity) is important to determine. It was shown that carboxylic ionophores can act in a very specific manner without any effects or morphological changes in 
uninfected erythrocytes $[81,98]$. However, mammalian lymphoblasts and macrophages have been found to be affected by certain polyether ionophores at $\mathrm{IC}_{50}$ concentrations that are at least 35-fold higher than those determined against P. falciparum [81].

The anti-malarial activity of polyether antibiotics against blood-stage malaria parasites seems to be due to their ionophoric properties [87]. $\mathrm{Na}^{+}$influx induced by these compounds is accompanied by an increase in intralysosomal $\mathrm{pH}$ (alkalinisation) which leads to inhibition of lysosomal haemoglobin degradation and finally to parasite cell death [87]. However, the possibility to treat selectively the trophozoite stage of $P$. falciparum using maduramicin $\left(\mathrm{EC}_{50}\right.$ value of $0.44 \mathrm{nM}$ ) has shed new light on the whole process [99]. Maduramicin, a sodium antiporter, is not likely to alter cytosolic $\mathrm{pH}$ but to increase the intracellular $\mathrm{Na}^{+}$concentration $\left(\mathrm{Na}^{+}\right.$influx) through inhibition of the putative $\mathrm{Na}^{+}$pump PfATP4 [99].

Of the semi-synthetic derivatives of polyether ionophores that have been tested for their anti-malarial activity, only some lasalocid acid and monensin analogues showed potent activity against selected Plasmodium species, including in vivo activity against $P$. berghei and P. chabaudi $[87,100]$. Six monensin carbamates (Figure 5, compounds 3-8) obtained by chemical modification of the hydroxyl group at the $\mathrm{C}(26)$ position showed in vivo antiplasmodial activity in mice experimental infected with malaria [100]. 

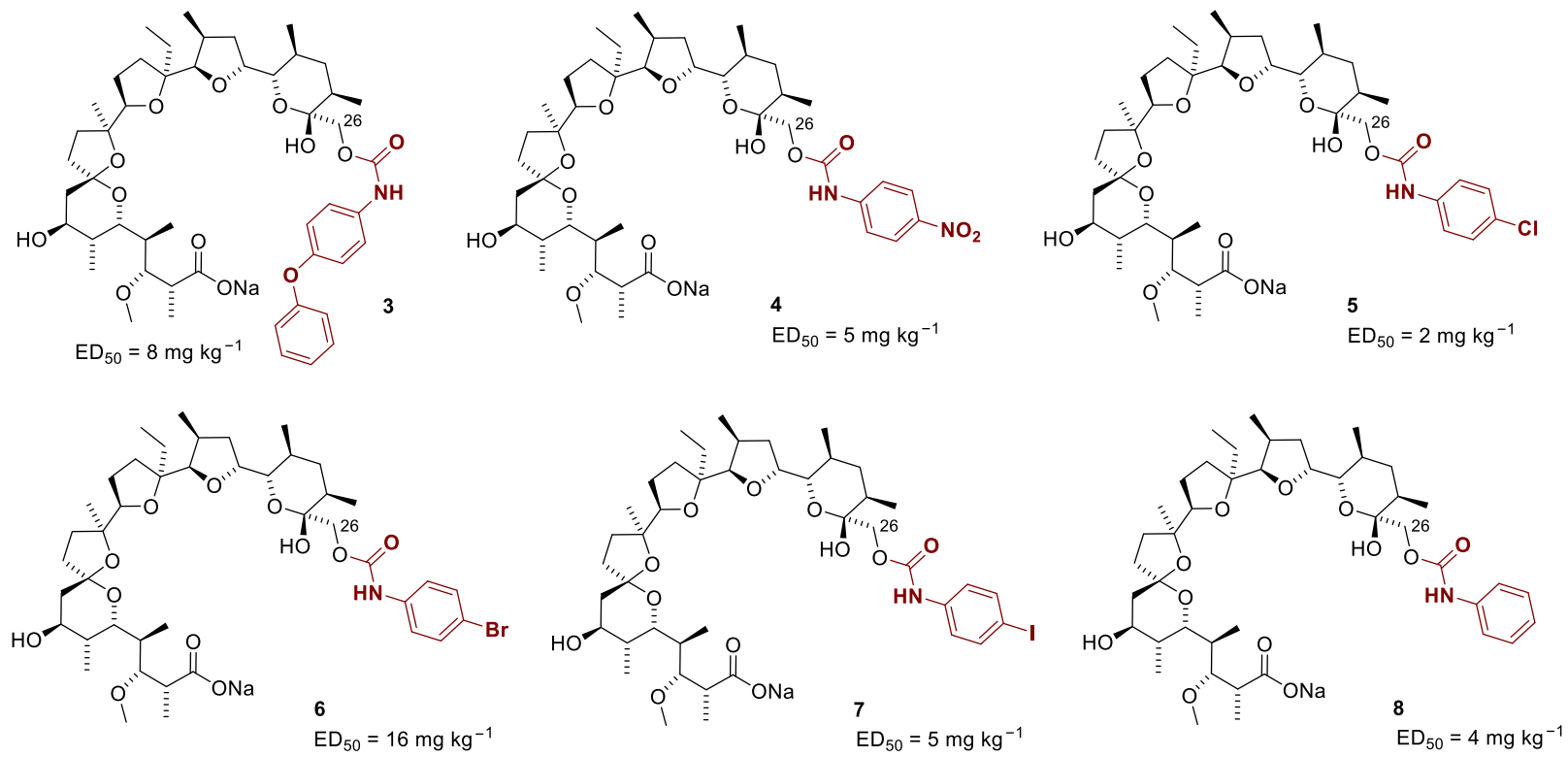

Activity in vitro (Plasmodium falciparum)
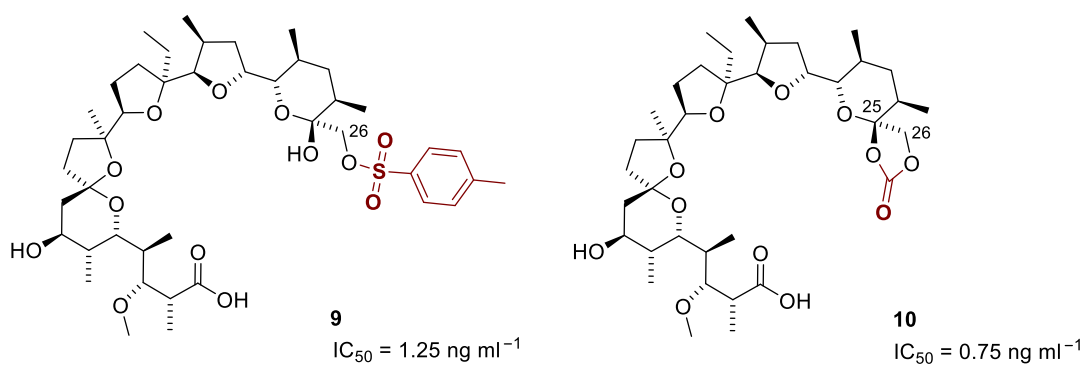

Figure 5. Structure of monensin derivatives with in vitro and in vivo anti-malarial activity surpassing that of the unmodified ionophore [100-102].

Chlorophenyl and phenyl carbamate derivatives of monensin (Figure 5, compounds 5 and $\mathbf{8}$, respectively) were identified to be the most active analogues against $P$. berghei, with activities 40-times higher compared to the unmodified parent compound [100]. Encouragingly, some of the monensin derivatives (Figure 5, chlorophenyl carbamate 5, sulphonate 9 and carbonate 10) displayed higher in vitro activity against $P$. falciparum than monensin itself [101,102]. The increased anti-plasmodial activity has been linked to a significant change in the ionophoric properties of the modified compounds. Monensin derivatives preferentially complex and transport potassium over sodium and this inversion of complexation selectivity is probably the reason for the increased biological activity of 
monensin semi-synthetic analogues [102]. To evaluate the therapeutic potential of monensin derivatives, the cytotoxicity of some analogues was also investigated [100]. Interestingly, the cytotoxicity of alkyl carbamates was significantly lower than that of unmodified monensin, while selected phenyl carbamates (Figure 5, compounds 3-5 and 7-8) displayed similar cytotoxicity than the parent compound [100]. The only exception was the bromophenyl carbamate derivative of monensin (Figure 5, compound 6), which was found to be about three times less toxic than the parent ionophore. In addition, this compound displayed activity against $P$. berghei in mice at a dose of $16 \mathrm{mg} \mathrm{kg}^{-1}$, whereas monensin was ineffective at dosages up to $100 \mathrm{mg} \mathrm{kg}^{-1}$ [100].

One of the derivatives of lasalocid acid, 5-bromolasalocid acid (Figure 6, compound 11), was also found to have a better therapeutic index than the parent ionophore as it exhibits stronger interactions with lipid membranes [81,89]. Overall, the acceptable levels of toxicity and the good in vitro and in vivo therapeutic window are the major advantages of analogue $\mathbf{1 1}$ (Figure 6) over unmodified lasalocid acid [81,89]. The group of polyether ionophore derivatives that show promise as basis for novel anti-malarial drug candidates should also include certain C(20)-amine analogues of salinomycin [103].

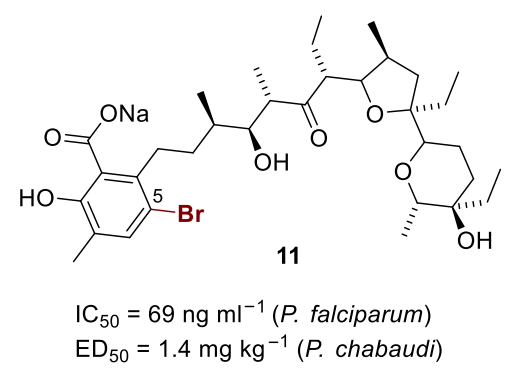

Figure 6. Structure of 5-bromolasalocid acid with potent anti-malarial activity $[81,89]$.

\subsubsection{Babesiosis}

Babesiosis is an intraerythrocytic parasitic disease caused by malaria-like protozoans of the genus Babesia [104,105] and these pathogens are believed to be the second most 
common blood parasites of mammals after trypanosomes [106]. Although more than 100 Babesia species have been reported up to now, relatively few have been identified as human pathogens, including B. microti, B. divergens and B. duncani [107,108]. Transmission of babesiosis is via bites of infected ticks (e.g. Ixodes scapularis). The ticks can be found in forested areas, in dense brushes and grasslands. As they require warm weather conditions, they occur especially in southern regions of Europe and in the Northeast and upper Midwest parts of the United States. In the rest of the world, human babesiosis is found more sporadically [109]. In 2014, a total number of 1744 new cases of human babesiosis were reported in the United States [110].

Clinically, Babesia infections display a broad spectrum of disease severity, from asymptomatic to even life-threatening [107]. Although many individuals infected with Babesia do not show any symptoms, some may develop mild to moderate viral-like illness with the occurrence of arthralgia, chills, fever, loss of appetite and myalgia [111]. Because Babesia parasites infect and destroy red blood cells, babesiosis can cause a special type of anaemia, known as haemolytic anaemia, which may result in jaundice (yellowing of the skin) and dark urine [112].

The cyclic polyether antibiotic valinomycin and carboxylic ionophore salinomycin (Figure 1) have been shown to exhibit potent in vitro anti-babesial activity against the related canine pathogen B. gibsoni [113]. Interestingly, depending on the type of red blood cells, both ionophores act in different ways [113]. In the case of the parasite infected erythrocytes containing low concentrations of potassium (which completely lack $\mathrm{Na}^{+} / \mathrm{K}^{+}$-ATPase activity), the ionophores did not affect the red blood cells (no changes in the intracellular concentrations of sodium, potassium and ATP, and no haemolysis was observed) but directly B. gibsoni, leading to the destruction of the pathogen [78]. On the other hand, if the parasite infected erythrocytes containing high concentrations of potassium (which contain $\mathrm{Na}^{+} / \mathrm{K}^{+}-$ 
ATPase activity), the ionophores increased the intracellular sodium concentration and lowered the intracellular concentrations of potassium and ATP, which led to the lysis of the red blood cells and subsequently to the killing of $B$. gibsoni. However, the in vitro anti-babesial activity of both polyether antibiotics was significantly weaker on infected erythrocytes containing high concentrations of potassium, probably because of the protection by the $\mathrm{Na}^{+} / \mathrm{K}^{+}$-ATPase activity of the host cell [113]. Whether the results obtained with B. gibsoni can be also applied to human erythrocytes infected with Babesia species remains to be shown.

\subsubsection{Toxoplasmosis}

Toxoplasma gondii is probably the world's most common protozoan parasites causing toxoplasmosis in animals and humans [114]. It can infect almost any cell from almost any warn-blooded animal but the final host are always domestic and wild cats, in which sexual reproduction takes place [115]. Humans contract toxoplasmosis by either ingesting vegetables or drinking water contaminated with oocysts, or by eating undercooked meat infected with the parasite [116]. T. gondii can also be congenitally transmitted from a mother to the developing foetus.

Although more than 60 million people may be infected with $T$. gondii alone in the United States [117], only a small percentage of them would have experienced flu-like symptoms, because the immune system keeps the infection usually under control [118]. Infection with $T$. gondii during the first trimester of pregnancy may cause severe neurological damage in the developing foetus and can result in stillbirth. Toxoplasmosis is particularly dangerous for immunocompromised individuals, like patients with HIV/AIDS or organ transplant recipients under immunosuppressant medication [114,119-121]. In these patients, a previous existing toxoplasmosis cannot be anymore controlled by their immune system, leading to full-blown disease. 
Usually, most healthy people do not need treatment for toxoplasmosis unless they show severe symptoms. In these cases of acute toxoplasmosis, patients can be treated with a co-therapy of pyrimethamine and sulfadiazine/clindamycin. Immunocompromised patients with toxoplasmosis need life-long chemotherapy. However, current anti- $T$. gondii chemotherapy is ineffective in the treatment of cerebral toxoplasmosis, a common complication in immunodeficient patients [51].

Of note is that polyether ionophore antibiotics have been shown to display activity against both tachyzoite and bradyzoite stages of $T$. gondii $[122,123]$. Monensin was found to inhibit the infectivity and viability of bradyzoites in vitro and in vivo [122]. Already at very low concentrations $\left(0.001 \mu \mathrm{g} \mathrm{m}^{-1}\right)$, monensin caused significant cytological changes in bradyzoites and induced swelling of the cells and the formation of large number of vacuoles in their cytoplasm [122]. Higher monensin concentrations led to lysis of bradyzoites [122]. These findings are consistent with results obtained from animal studies [124-126]. Prophylactic treatment of ewes with monensin was shown to reduce the neonatal mortality due to toxoplasmosis [126]. After administration of daily doses of monensin of $16.8 \mathrm{mg}$ or $27.9 \mathrm{mg}$, ewes had fewer abortions than untreated controls; lamb mortality was $16.7 \%$ in ewes fed with monensin compared to $55.2 \%$ in control ewes [126]. On the other hand, lasalocid acid (Figure 1) did not reduced the rate of abortion and neonatal mortality in sheep infected with T. gondii [125].

Mechanistically, it was shown that the toxoplasmicidal action of monensin is rapid and independent of the metabolic activity of the bradyzoites [127], and due to arresting T. gondii at an apparent late-S-phase cell cycle checkpoint [128]. Experiments with monensin-resistant T. gondii strains indicated that this effect of monensin is dependent on the function of a mitochondrial homologue of the MutS DNA damage repair enzyme TgMSH-1 [128]. Interestingly, the same TgMSH-1-dependent cell cycle arrest was also observed with 
salinomycin [128]. Other mechanisms of toxoplasmicidal action of monensin, including the induction of autophagy and the initiation of marked morphological changes in the parasite's mitochondria, have also been reported $[129,130]$. Remarkably, monensin was found not to induce autophagy in a parasite strains deficient in the mitochondrial DNA repair enzyme TgMSH-1 [130]. Thus, it was suggested that TgMSH-1 either mediates cell cycle arrest and autophagy independently, or autophagy occurs downstream of cell cycle arrest in a manner similar to apoptosis of cells arrested in G2 of the cell cycle [130].

\subsubsection{Neosporosis}

Neosporosis is a disease caused by infection with Neospora caninum, which is often misidentified as Toxoplasma gondii because of structural, genetic and immunological similarities between the two protozoans [131,132]. Generally, neosporosis is an asymptomatic disease in adult animals, and for this reason, it is more frequently diagnosed in young animals [131]. Infection with the parasite leads to profound defects in the central nervous system and death, especially in dogs. Blindness, hepatitis (yellow eyes and skin), paralysis and respiratory failure are frequently observed symptoms as well [133,134]. In addition, neosporosis is a major cause of abortion in cattle and for high mortality rates in calves globally [135-137].

During an extensive screening study, a series of 43 different chemotherapeutics, including various anti-protozoal agents, dihydrofolate reductase/thymidylate synthase inhibitors, lincosamides, macrolides, pentamidine analogues, sulphonamides as well as six carboxylic polyether ionophores, were identified to display activity against $N$. caninum [138]. Noteworthy, five of the polyether antibiotics, namely lasalocid acid, maduramicin, monensin, narasin and salinomycin (Figure 1), showed 100\% reduction in tachyzoite induced lesions at concentrations of about $10^{-6} \mu \mathrm{g} \mathrm{m} l^{-1}[51,138]$. 


\subsubsection{Coccidiosis}

Coccidiosis is a parasitic disease that globally affects domestic animals [139]. The disease causes considerable economic losses in the poultry industry, but also in livestock farming of cattle, goats, pigs, rabbits and sheep [140,141]. The global economic losses from coccidiosis are estimated to be 3 billion \$ per year [139].

Coccidiosis is usually an acute invasion and destruction of the intestinal epithelium and the underlying connective tissue of the mucosa caused by protozoans of the genus Eimeria, which results in diarrhoea, impaired feed conversion, and general weakness $[142,143]$. Other clinical signs include haemorrhage into the lumen of the intestine, catarrhal inflammation, emaciation, fever, inappetence, weight loss, poor growth, and in extreme cases, death of infected animals $[55,144]$.

In most countries, the preferred method for the control of coccidiosis involves adding appropriate anti-coccidial agents in the feed [145]. As already mentioned, polyether ionophores have found commercial use in veterinary medicine to improve feed metabolism in ruminants, but also as feed additive to control coccidiosis (Table 2). These prophylactic and therapeutic uses of polyether ionophores are the first approved applications of this group of compounds [146-148].

Monensin and salinomycin (Figure 1) in the form of their sodium salts are potent anticoccidial agents effective against various coccidiosis-causing parasites, including $E$. acervulina, E. brunette, E. maxima, E. necatrix and E. tenella [149-153]. Importantly, both carboxylic ionophores are more potent as anti-coccidial agents than many other commonly used drugs to treat coccidiosis [149-153]. Salinomycin effectively reduces mortality rates and leads to a notable increase in average body weight in infected chicken, compared to untreated infected controls [154]. 
Coccidiostatic tests of semduramicin (Figure 1) against a series of laboratory isolates of Eimeria species have clearly demonstrated the activity of this ionophore at concentrations ranging from $20 \mathrm{ppm}$ to $30 \mathrm{ppm}$ [155]. In another study, the activity of 13 anti-coccidials currently used in domestic poultry, including lasalocid acid, monensin, narasin (in combination with nicarbazin), salinomycin and semduramicin (alone or in combination with roxarsone) (Figure 1), were investigated to check whether the agents were effective at controlling E. lettyae-infections in the northern bobwhite (Colinus virginianus) [156]. Excellent to good efficacy (150 ppm) was found for the two ionophore antibiotics lasalocid acid and narasin in combination with nicarbazin, while only marginal protection of the birds were observed for monensin, salinomycin, and semduramicin alone or in combination with roxarsone [156]. Recently, lasalocid acid (120 ppm) and three other ionophores displayed moderate effectiveness in reducing lesions as well as improving weight gains in the chukar partridge (Alectoris chukar) infected with E. kofoidi or E. legionensis, or with both species together [157].

Clinically important is the often observed lethal interactions between certain ionophore anti-coccidials and the antibiotic tiamulin in chickens and turkeys. This incompatibility has been well established for monensin, narasin and salinomycin, and to a much lesser extent for maduramicin and semduramicin (Figure 1) [158]. In contrast, lasalocid acid seems to be compatible with tiamulin [158]. Although the nature of the interaction remains unknown, it has been suggested that tiamulin may reduce metabolic degradation and excretion of ionophores, leading to clinical signs of overdosage in animals [158]. This suggestion is in agreement with the observation that the same toxic signs (ataxia, locomotor disturbances, loss of appetite and neurotoxicity) have been seen after administration of the polyether antibiotics alone at high dosages or after co-treatment with tiamulin at standard usage levels [158]. 
Mechanistically, the coccidiocidal action of polyether ionophores involves disruption of ion transport across the cell membrane of the parasites [145], and is generally directed against sporozoites (the infectious life cycle stage of the parasites taken up by the host from the environment) and preventing them to infect intestinal host cells $[145,159]$. However, it is believed that the anti-coccidial action of the ionophores does not result in a complete prevention of infection but rather permits low levels of parasitaemia, thereby allowing some degree of immunity to develop within the host [55]. In addition to the effects against sporozoites, monensin has been found to be also effective against merozoites, the life-cycle stage forms that are released into the intestinal lumen after merogony in gut cells $[145,160]$. It has been suggested that the anti-coccidial activity of monensin may be due to blocking the development of trophozoites during merogony, which would reduce the proliferation of the parasites within the host $[50,161,162]$.

An interesting finding is the observation that certain carbamates of monensin (Figure 7, compounds 12-14) were found to show higher in vivo anti-coccidial activity than the unmodified ionophore [100]. For example, halogenate phenylurethane derivatives of monensin displayed about two times higher coccidiostatic activity compared to the parent compound in chicks infected with E. tenella [100]. 

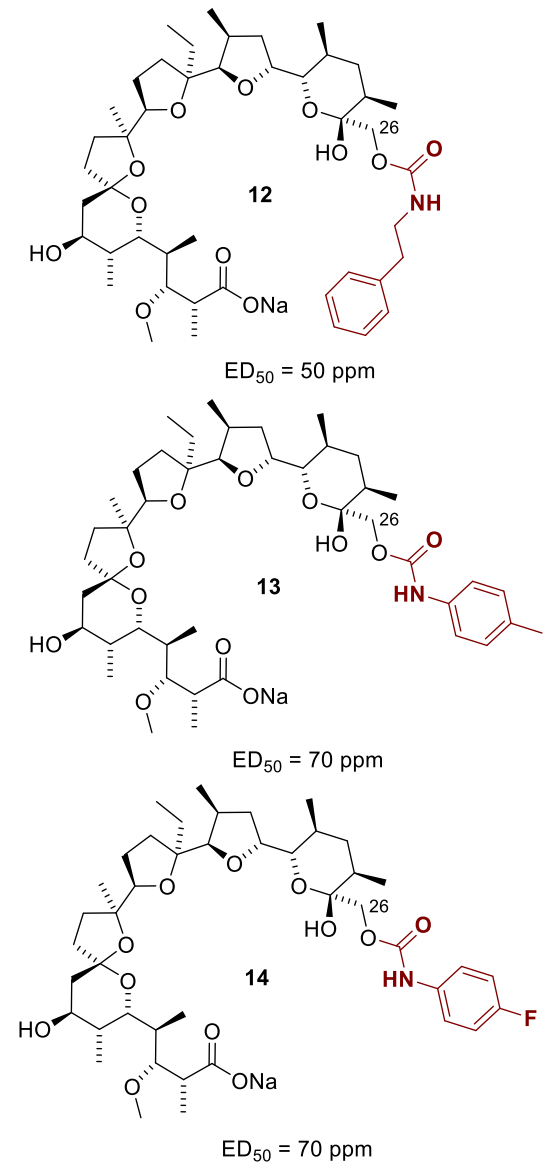

Figure 7. Structure of monensin carbamates with potent in vivo anti-coccidial activity [100].

A recently published patent related to novel monensin derivatives (Figure 8) describes the usage of these compounds for prevention, treatment or otherwise control of protozoans, including coccidia [163]. It has been demonstrated that compounds 15-18 (Figure 8) showed a significant activity towards E. tenella with very low cytotoxicities [163]. At relatively high concentrations, greater than or equal to $12.5 \mathrm{mg} \mathrm{ml}^{-1}$, monensin lactone (Figure 8, compound 15) appeared to inhibit significantly the development of E. tenella in cell culture by the inhibition of the formation of merozoites. Promisingly, also compound 16 (Figure 8) showed a very high efficacy against the parasite and was able to block the development of E. tenella in vitro, leading to the disappearance of schizonts and merozoites [163]. Importantly, at very low concentrations (lower than $0.39 \mathrm{mg} \mathrm{ml}^{-1}$ ), compounds 17 and 18 (Figure 8) demonstrated significant efficacy against E. tenella as well [163]. 


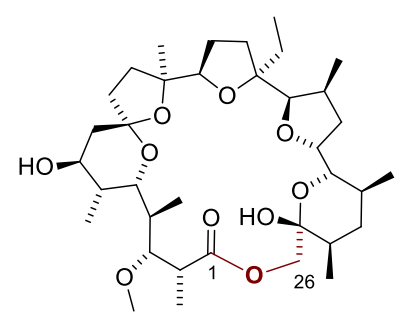

15

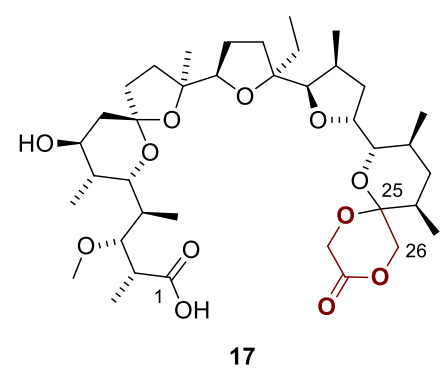

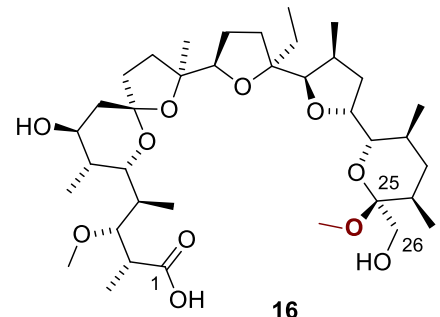

16

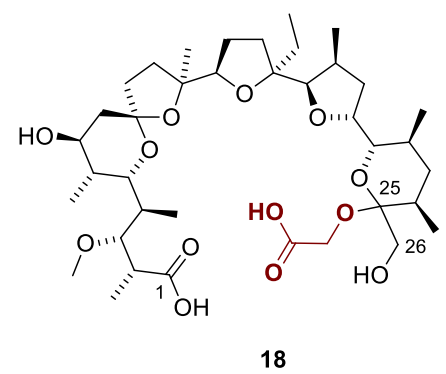

Figure 8. The structure of monensin derivatives tested for their activity against E. tenella [163].

The anti-coccidial action of C(20) salinomycin esters (Figure 9, compounds 19-26) has been assessed in chickens infected with E. tenella oocysts $\left(5 \cdot 10^{4}\right.$ sporulated oocysts per bird) [164]. The compounds were mixed with the feed and given ad libitum. The anticoccidial effect was determined by parameters, such as lesion scores, morbidity due to the infection, average weight gain and reduction in oocyst release on days six and seven post infection compared to untreated infected controls [164]. At $60 \mathrm{ppm}$, salinomycin sodium salt exhibited the best anti-coccidial effect, whereas salinomycin potassium salt produced weight loss due to drug toxicity [164].

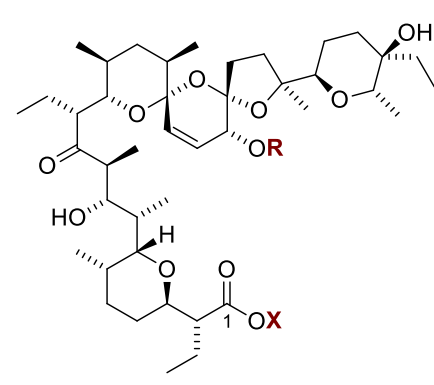

$\mathrm{X}=\mathrm{H}$ salinomycin acid $X=N a$ salinomycin sodium salt

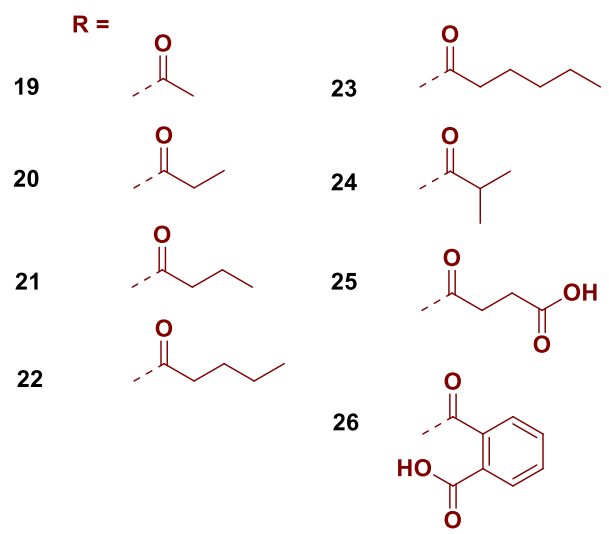

Figure 9. C(20) salinomycin esters with potent anti-coccidial activity [164]. 
Among the unbranched $O$-acyl derivatives of salinomycin (Figure 9, compounds 1923) in their free acid form $(X=H)$, a maximum activity was observed for compound 20, which was twice as active as salinomycin. In turn, the isobutyrate ester $\mathbf{2 4}$ (Figure 9) was about six times more active than salinomycin [164]. On the other hand, a decreased biological effect was observed for both dicarboxylic acid compounds 25 and 26 (Figure 9) [164]. The less pronounced activities of these derivatives might be explained by their hydrophilicity, which could disturb the transport through lipophilic cell membranes. The importance of evaluating counter ion effects $\left(\mathrm{H}^{+}, \mathrm{Na}^{+}, \mathrm{K}^{+}\right)$on the biological activity of the salinomycin derivatives was also demonstrated [164].

\subsubsection{Cryptosporidiosis}

Cryptosporidiosis is a potentially severe and life-threating parasitic disease caused by protozoans of the genus Cryptosporidium [165,166]. Cryptosporidiosis in farm and wild animals is associated with weight loss and mortality, but may also cause zoonotic infections in humans [167-169]. It is one of the most common waterborne diseases in humans, and can be found worldwide in both recreational and drinking water [170]. The disease is transmitted by ingestion of food or water contaminated with oocysts shed by infected animals or humans, or by smear infections [171].

The disease affects the distal small intestine and can also affect the respiratory tract, resulting in persistent watery diarrhoea with or without an unexplained cough, vomiting, dehydration, fatigue, nasal discharge, nausea, raised temperature, voice change and weight loss [172-175]. In both young children and immunosuppressed individuals, especially HIV/AIDS-positive and transplant patients, the symptoms are particularly severe and may lead to nutritional stunting and relatively high mortality rates, respectively [172-175]. Among 
all identified species, C. hominis and C. parvum are responsible for more than $90 \%$ of human cases of cryptosporidiosis [176].

Some carboxylic polyether antibiotics have been shown to be highly active against $C$. parvum both in vitro and in vivo [177-186], among which maduramicin and monensin (Figure 1) were identified as the most active ones [177-180,183-186]. Monensin was found to impair parasite development in cell cultures in a dose-dependent manner. At $0.144 \mu \mathrm{M}$, monensin inhibited the development of the parasite by $98 \%$ without any detectable morphological alterations of the host cells [179]. These observations are consistent with other reported data showing that parasite development is completely inhibited by monensin at 0.134 $\mu \mathrm{M}$ without any adverse effects to the host cells [178]. Maduramicin was shown to reduce the faecal parasite load by $96 \%$ [183].

Another study has shown a very potent synergistic effect of monensin in combination with the coccidiostatic agent toltrazuril against $C$. parvum oocysts; in combination, both agents were more effective than each of them alone [187]. In addition, monensin was found to display higher anti-cryptosporidial activity than toltrazuril at the same concentration [187].

Most new anti-cryptosporidial drug candidates for potential use in humans, including polyether ionophores, have been so far tested only in cell culture experiments $[188,189]$. However, a few polyether ionophores, including lasalocid acid and maduramicin (Figure 1), have been tested in a small number of patients with AIDS-related cryptosporidiosis, but unfortunately they failed to show any therapeutic effects [188].

Lasalocid acid has been reported to display anti-cryptosporidial activity both in vitro and in experimental-infected animals [190,191]. This includes studies that examined the effectiveness of lasalocid acid as novel agent against cryptosporidiosis in calves [190]. In addition, lasalocid acid was identified in a rat model as that agent that produced the highest anti-cryptosporidial effect among other chemotherapeutics tested [191]. 


\subsubsection{Sarcocystosis}

Sarcocystis species is a faecal-orally transmitted parasite of considerable veterinary economic and public health importance, which infects skeletal muscles of a wide-range of wild and domestic animals [192]. Moreover, this parasite may easily cross the blood-brain barrier, resulting in fatal inflammation of the brain and spinal cord (encephalomyelitis) [193]. Sarcocystis species require two hosts to complete their life cycle and humans can serve as the definitive host of the parasite [194]. Eating raw or undercooked beef and pork containing mature cysts of $S$. hominis or S. suihominis may lead to infection of humans with the parasites causing intestinal and muscular sarcocystosis [195,196].

For chemotherapy, the use of various anti-coccidials is usually recommended to treat sarcocystosis. Thus, carboxylic ionophores have been tried in a few instances to treat sarcocystosis in animals. For example, maduramicin (Figure 1) at a dose of $150 \mathrm{mg} \mathrm{kg}^{-1}$ given orally to pups experimentally infected with Sarcocystis for 5 days starting from the day when sporocysts were found in the faeces for the first time, resulted in almost $97 \%$ reduction in sporocysts production [197,198]. Salinomycin (Figure 1) has been shown to prevent or to reduce acute sarcocystosis in some domestic animals [194,199,200]. At a dosage of 4 and 5 $\mathrm{mg} \mathrm{kg}-1$, salinomycin was found to treat effectively experimental sarcocystosis in dogs and goats, respectively $[197,201]$.

To date, it was assumed that polyether ionophore antibiotics should only be effective in treating intestinal stages of Sarcocystis during the acute phase [194], and should show no effect in treating acute muscular sarcocystosis. However, when animals were given salinomycin together with an infectious dose of Sarcocystis, the development of muscular sarcocystosis was prevented [200]. When lambs infected with S. tenella were treated for 29 days with salinomycin, clinical sarcocystosis was reduced, but the completion of the life cycle 
of some parasites was not fully blocked [200]. Encouragingly is the observation that when these lambs were challenged with 1 million of $S$. tenella sporocysts 63 days after the initial infection, they were found to have developed protective immunity [200].

\subsection{Marine white spot disease}

Marine white spot disease, also known as saltwater ich or marine ich, is one of the most common and persistent diseases that infect cultured and wild marine fishes in home aquariums and aquaculture environments worldwide [202]. It is caused by an infection with Cryptocaryon irritans, a ciliated protozoan that is present in all saltwater environments [203,204]. This widespread protozoan penetrates the skin and gills of the fish, which, depending on the immune status of the affected host, may cause a wide spectrum of symptoms. In mild cases, the symptoms may just include a few pinhead-sized $(0.5-2.0 \mathrm{~mm})$ white spots, nodules or patches, while in more severe cases they comprise irritation, lethargy, loss of appetite, disruption of osmoregulation and respiratory distress, and even death [205].

Polyether ionophores have been identified as lead candidates for chemotherapy against cryptocaryoniasis as two of them, narasin and salinomycin (Figure 1), have been shown to kill C. irritans and to inhibit the growth of trophonts (adult, motile life-cycle stage of ciliate protozoans) both in vitro and in vivo [206]. In in vitro studies, it was found that narasin and salinomycin displayed high anti-parasitic activity at concentrations as low as $0.2 \mu \mathrm{M}$, while monensin (Figure 1) showed a direct killing effect on C. irritans at a higher concentration of $2 \mu \mathrm{M}$ [206]. During in vivo experiments, it was observed that fish that were fed a diet medicated with salinomycin survive longer than a control group on unmedicated diet [206].

\subsection{Schistosomiasis}


Schistosomiasis, also known as bilharzia, bilharziasis or snail fever, is an acute and chronic disease caused by parasitic flatworms (trematodes) of the genus Schistosoma [207,208]. Schistosomiasis is the second most devastating tropical disease in the world after malaria $[209,210]$. According to the WHO, the total number of people in need of preventive chemotherapy for schistosomiasis was 207.7 million in 2016, of which 111.8 million were school-aged children, especially those from developing countries in Africa, Asia, South America and the Caribbean region [211].

People usually acquire schistosomiasis when they come in contact with fresh water contaminated with the larval forms of the parasite [211,212]. Symptoms include abdominal pain, bloody stool, haematuria (blood in the urine) and diarrhoea [212,213]. After a few weeks from the initial infection, acute schistosomiasis (Katayama fever) may occur. The typical symptoms of acute schistosomiasis include fever, urticarial, enlarged liver and spleen, and bronchospasm [214]. In children, who are especially vulnerable to bilharzia, it may cause poor growth and learning difficulty as well $[215,216]$.

It has been shown that the polyether ionophore lasalocid acid (Figure 1) possesses great promise as potential schistosomacidal agent. At a dosage of $100 \mathrm{mg} \mathrm{kg} \mathrm{kg}^{-1}$, lasalocid acid was found to decrease significantly the worm burden (female worms, 41\%; male worms, $44 \%$ ) in in vivo studies compared to controls [217]. In addition, the ionophore also improved the organ pathology and was well tolerated by mice infected with the parasite [217]. For salinomycin (Figure 1), results from in vitro studies indicated a rather weak response $\left(\mathrm{IC}_{50}=\right.$ 32.6 $\mu \mathrm{M})$ against schistosomula, the immature form of the parasite in humans [218].

\section{Conclusions}

The best way to control effectively any parasitic disease is to improve the living standards of people living in underdeveloped countries by raising economic growth. However, 
it is not an easy task and requires substantial financial investments. Parasitic diseases have considerable effects on both the economy and public health, and many parasitoses cause more morbidity than mortality. In children, parasitic diseases can cause anaemia, stunting and learning difficulties, although most of these effects are usually reversible with treatment. Early diagnosis of individuals with any parasitic disease is very important in order to prevent any complications. Due to the lack of vaccines, effective chemotherapies are crucial to treat successfully patients affected by parasitic diseases. Unfortunately, most commonly used antiparasitic drugs are outdated and show problems with toxicity. In addition, the large-scale and long-term use of key drugs has led to the development of drug-resistant parasites. Therefore, the search for new generation, highly active and tolerable anti-parasitic agents is of pivotal importance in the fight against parasitic diseases.

Research over the last years have indicated that polyether ionophore antibiotics and their derivatives are promising anti-parasitic drug candidates. Of particular interest are six ionophores, namely lasalocid acid, maduramicin, monensin, narasin, salinomycin and semduramicin, as they are widely used in veterinary sector as non-hormonal growth promoters and anti-coccidial medicines. In addition to their industrial use, these polyether ionophores have been shown to display promising activity against a variety of parasites, including trypanosomiasis, leishmaniasis, malaria, babesiosis, cryptosporidiosis, toxoplasmosis, and schistosomiasis (Table 3). 
Table 3. Summary of the anti-parasitic activity of carboxylic polyether ionophores.

\begin{tabular}{|c|c|c|}
\hline $\begin{array}{c}\text { Parasitic } \\
\text { disease }\end{array}$ & Disease & $\begin{array}{l}\text { Polyether } \\
\text { ionophore }\end{array}$ \\
\hline \multirow{2}{*}{$\begin{array}{l}\text { Kinetoplastid } \\
\text { diseases }\end{array}$} & $\begin{array}{c}\text { African } \\
\text { trypanosomiasis }\end{array}$ & $\begin{array}{l}\text { lasalocid acid } \\
\text { monensin } \\
\text { salinomycin }\end{array}$ \\
\hline & Leishmaniasis & $\begin{array}{c}\text { monensin } \\
\text { narasin } \\
\text { salinomycin }\end{array}$ \\
\hline \multirow{10}{*}{$\begin{array}{l}\text { Apicomplexan } \\
\text { diseases }\end{array}$} & Malaria & $\begin{array}{l}\text { lasalocid acid } \\
\text { maduramicin } \\
\text { monensin } \\
\text { narasin } \\
\text { salinomycin }\end{array}$ \\
\hline & Coccidiosis & $\begin{array}{l}\text { lasalocid acid } \\
\text { maduramicin } \\
\text { monensin } \\
\text { narasin } \\
\text { salinomycin } \\
\text { semduramicin }\end{array}$ \\
\hline & Babesiosis & salinomycin \\
\hline & Toxoplasmosis & $\begin{array}{c}\text { lasalocid acid } \\
\text { monensin }\end{array}$ \\
\hline & Neosporosis & $\begin{array}{l}\text { lasalocid acid } \\
\text { maduramicin } \\
\text { monensin } \\
\text { narasin } \\
\text { salinomycin }\end{array}$ \\
\hline & Cryptosporidiosis & $\begin{array}{c}\text { lasalocid acid } \\
\text { maduramicin } \\
\text { monensin }\end{array}$ \\
\hline & Sarcocystosis & $\begin{array}{c}\text { maduramicin } \\
\text { salinomycin }\end{array}$ \\
\hline & Neosporosis & $\begin{array}{l}\text { lasalocid acid } \\
\text { maduramicin } \\
\text { monensin } \\
\text { narasin } \\
\text { salinomycin }\end{array}$ \\
\hline & $\begin{array}{c}\text { Marine white spot } \\
\text { disease }\end{array}$ & $\begin{array}{c}\text { narasin } \\
\text { salinomycin }\end{array}$ \\
\hline & Schistosomiasis & $\begin{array}{c}\text { lasalocid acid } \\
\text { salinomycin }\end{array}$ \\
\hline
\end{tabular}

Some derivatives of these ionophores show even better anti-parasitic activities compared to their unmodified parent compounds. The increased efficiency and selectivity 
demonstrated for some polyether ionophore derivatives against various parasites, including trypanosomes and apicomplexans, clearly indicates the huge potential of this group of compounds, which should provide innovative ideas for the rational development of new analogues in the coming years.

\section{Dedication}

We would like to dedicate this article to Professor Bogumił Brzezinski in honour of his $75^{\text {th }}$ birthday.

\section{Acknowledgment}

M.A. wishes to acknowledge the Polish Science Centre (NCN) for financial support by a SONATA grant (2016/23/D/ST5/00242) and the Foundation for Polish Science (FNP) for a START scholarship.

\section{References}

[1] A. Alum, J.R. Rubino, M. Khalid Ijaz, The global war against intestinal parasites - should we use a holistic approach? Int. J. Infect. Dis. 14 (2010) e732-e738.

[2] B. Choi, B. Kim, Prevalence and risk factors of intestinal parasite infection among schoolchildren in the peripheral highland regions of Huanuco, Peru, Osong. Public Health Res. Perspect. 8 (2017) 302-307.

[3] Y. Wang, Introduction to parasitic disease, in: H. Li (Ed.), Radiology of parasitic diseases, Springer, Dordrecht, 2017.

[4] E.-T. Piperaki, P.T. Tassios, Parasitic infections: their position and impact in the postindustrial world, Clin. Microbiol. Infect. 22 (2016) 469-470.

[5] A. Karan, G.B. Chapman, A. Galvani, The influence of poverty and culture on the transmission of parasitic infections in rural Nicaraguan villages, J. Parasitol. Res. 2012 (2012) 478292.

[6] PLoS Blogs Network - Speaking of Medicine. One Million Deaths By Parasites, [on-line access: 201810-09]. https://blogs.plos.org/ 
[7] A.B. Bhatti, M. Usman, V. Kandi, Current scenario of HIV/AIDS, treatment options, and major challenges with compliance to antiretroviral therapy, Cureus 8 (2016) e515.

[8] C. Afoakwah, X. Deng, I. Onur, Malaria infection among children under-five: The use of large-scale interventions in Ghana, BMC Public Health 18 (2018) 536.

[9] D. Roberts, G. Matthews, Risk factors of malaria in children under the age of five years old in Uganda, Malar. J. 15 (2016) 246.

[10] J.F. May, World population policies: Their origin, evolution, and impact, Springer Science \& Business Media, 2012.

[11] World Health Organization - Malaria, [on-line access: 2018-10-09]. http://www.who.int/malaria/en/

[12] R. Haque, Human intestinal parasites, J. Health Popul. Nutr. 25 (2007) 387-391.

[13] D.W. Crompton, L. Savioli, Intestinal parasitic infections and urbanization, Bull. World Health Organ. $71(1993) 1-7$.

[14] A.F. Cowman, J. Healer, D. Marapana, K. Marsh, Malaria: Biology and disease, Cell 167 (2016) 610624.

[15] P.A. Buffet, I. Safeukui, G. Deplaine, V. Brousse, V. Prendki, M. Thellier, G.D. Turner, O. MercereauPuijalon, The pathogenesis of Plasmodium falciparum malaria in humans: Insights from splenic physiology, Blood 117 (2011) 381-392.

[16] S.K. Shankar, V. Suryanarayana, S. Vasantha, V. Ravi, B.V. Ravi Kumar, Biology of neurocysticercosis - Parasite related factors modulating host response, Med. J. Armed Forces India 50 (1994) 79-88.

[17] P.J. Hotez, Ten failings in global neglected tropical diseases control, PLoS Negl. Trop. Dis. 11 (2017) e0005896.

[18] P.J. Hotez, Ten global "hotspots" for the neglected tropical diseases, PLoS Negl. Trop. Dis. 8 (2014) e2496.

[19] I. Abdullah, H. Tak, F. Ahmad, N. Gul, S. Nabi, T.A. Sofi, Predominance of gastrointestinal protozoan parasites in children: A brief review, Int. J. Vet. Sci. Anim. Husb. 1 (2016) 1-6.

[20] S.M. Fletcher, D. Stark, J. Harkness, J. Ellis, Enteric protozoa in the developed world: A public health perspective, Clin. Microbiol. Rev. 25 (2012) 420-449. 
[21] L.-G. Song, X.-D. Zeng, Y.-X. Li, B.-B. Zhang, X.-Y. Wu, D.-J. Yuan, A. He, Z.-D. Wu, Imported parasitic diseases in mainland China: Current status and perspectives for better control and prevention, Infect. Dis. Poverty 7 (2018) 78.

[22] F.F. Norman, B. Monge-Maillo, Á. Martínez-Pérez, J.A. Perez-Molina, R. López-Vélez, Parasitic infections in travelers and immigrants: Part I protozoa, Fut. Microbiol. 10 (2015) 69-86.

[23] K.J. Prasad, Emerging and re-emerging parasitic diseases, JIMSA 23 (2010) 45-50.

[24] A.G. Peniche, A.R. Renslo, P.C. Melby, B. L. Travi, Antileishmanial activity of disulfiram and thiuram disulfide analogs in an ex vivo model system is selectively enhanced by the addition of divalent metal ions, Antimicrob. Agents Chemother. 59 (2015) 6463-6470.

[25] M. Wink, Medicinal plants: A source of anti-parasitic secondary metabolites, Molecules 17 (2012) 12771-12791.

[26] S. Tagboto, S. Townson, Antiparasitic properties of medicinal plants and other naturally occurring products, Adv. Parasitol. 50 (2001) 199-295.

[27] H.P. de Koning, Drug resistance in protozoan parasites, Emerg. Top. Life Sci. 1 (2017) 627-632.

[28] C.H. Sibley, S.Y. Hunt, Drug resistance in parasites: Can we stay ahead of the evolutionary curve? Trends Parasitol. 19 (2003) 532-537.

[29] M. Ouellette, Biochemical and molecular mechanisms of drug resistance in parasites, Trop. Med. Int. Health 6 (2001) 874-882.

[30] A. Huczyński, Polyether ionophores - promising bioactive molecules for cancer therapy, Bioorg. Med. Chem. Lett. 22 (2012) 7002-7010.

[31] C.J. Dutton, B.J. Banks, C.B. Cooper, Polyether ionophores, Nat. Prod. Rep. 12 (1995)165-181.

[32] J. Rutkowski, B. Brzezinski, Structures and properties of naturally occurring polyether antibiotics, Biomed. Res. Int. 2013 (2013) 162513.

[33] J.W. Westley, Polyether antibiotics: Naturally occurring acid ionophores, in: J.W. Westley (Ed.), Biology, Vol. 1, Marcel Dekker, Inc., New York, 1982.

[34] J.W. Westley, Polyether antibiotics: Naturally occurring acid ionophores, in: J.W. Westley (Ed.), Biology, Vol. 2, Marcel Dekker, Inc., New York, 1983.

[35] M. Antoszczak, J. Rutkowski, A. Huczyński, Structure and biological activity of polyether ionophores and their semi-synthetic derivatives, in: G. Brahmachari (Ed.), Bioactive natural products. Chemistry and biology, Weinheim, 2015. 
[36] A. Huczyński, Salinomycin - A new cancer drug candidate, Chem. Biol. Drug Des. 79 (2012) $235-238$.

[37] S.M. Johnson, J. Herrin, S.J. Liu, I.C. Paul, Crystal structure of a barium complex of antibiotic X-537A, $\mathrm{Ba}\left(\mathrm{C}_{34} \mathrm{H}_{53} \mathrm{O}_{8}\right)_{2} \cdot \mathrm{H}_{2} \mathrm{O}$, Chem. Soc. D, 0 (1970) 72-73.

[38] A. Huczyński, M. Ratajczak-Sitarz, A. Katrusiak, B. Brzezinski, Molecular structure of the 1:1 inclusion complex of monensin A sodium salt with acetonitrile, J. Mol. Struct. 832 (2007) 84-89.

[39] E.F. Paulus, M. Kurz, H. Matter, L. Vértesy, Solid-state and solution structure of the salinomycinsodium complex: Stabilization of different conformers for an ionophore in different environments, J. Am. Chem. Soc. 120 (1998) 8209-8221.

[40] A. Huczyński, M. Ratajczak-Sitarz, J. Stefańska, A. Katrusiak, B. Brzezinski, F. Bartl, Reinvestigation of the structure of monensin A phenylurethane sodium salt based on X-ray crystallographic and spectroscopic studies, and its activity against hospital strains of methicillin-resistant $S$. epidermidis and S. aureus, J. Antibiot. (Tokyo) 64 (2011) 249-256.

[41] M. Dobler, Natural cation-binding agents, in: G.W. Gokel (Ed.), Comprehensive supramolecular chemistry: Molecular recognition: Receptors for cationic guests, Vol. 1, Pergamon, New York, 2004.

[42] L.F. Lindoy, Outer-sphere and inner-sphere complexation of cations by the natural ionophore lasalocid A, Coord. Chem. Rev. 148 (1996) 349-368.

[43] M. Inabayashi, S. Miyauchi, N. Kamo, T. Jin, Conductance change in phospholipid bilayer membrane by an electroneutral ionophore, monensin, Biochemistry 34 (1995) 3455-3460.

[44] H. Tsukube, K. Takagi, T. Higashiyama, T. Iwachido, N. Hayama, Biomimetic membrane transport: Interesting ionophore functions of naturally occurring polyether antibiotics toward unusual metal cations and amino acid ester salts, Inorg. Chem. 33 (1994) 2984-2987.

[45] H.H. Mollenhauer, D.J. Morre, L.D. Rowe, Alteration of intracellular traffic by monensin; Mechanism, specificity and relationship to toxicity, Biochim. Biophys. Acta 1031 (1990) 225-246.

[46] B.C. Pressman, Antibiotics and their complexes, Marcel Dekker, New York, 1985.

[47] J.W. Westley, The polyether antibiotics: Monocarboxylic acid ionophores, Annu. Rep. Med. Chem. 10 (1975) 246-256.

[48] Y.N. Antonenko, T.I. Rokitskaya, A. Huczyński, Electrogenic and nonelectrogenic ion fluxes across lipid and mitochondrial membranes mediated by monensin and monensin ethyl ester, Biochim. Biophys. Acta (BBA) Biomembr. 1848 (2015) 995-1004. 
[49] A. Huczyński, J. Janczak, D. Łowicki, B. Brzezinski, Monensin A acid complexes as a model of electrogenic transport of sodium cation, Biochim. Biophys. Acta (BBA) Biomembr. 1818 (2012) 2108-2119.

[50] D. Łowicki, A. Huczyński, Structure and antimicrobial properties of monensin A and its derivatives: Summary of the achievements, BioMed Res. Int. 2013 (2013) 742149.

[51] D.A. Kevin II, D.A.F. Meujo, M.T. Hamann, Polyether ionophores: Broad-spectrum and promising biologically active molecules for the control of drug-resistant bacteria and parasites, Expert Opin. Drug Discov. 4 (2009) 109-146.

[52] V. Kaushik, J.S. Yakisich, A. Kumar, N. Azad, A.K.V. Iyer, Ionophores: Potential use as anticancer drugs and chemosensitizers, Cancers 10 (2018) 360.

[53] M. Antoszczak, A. Huczyński, Anticancer activity of polyether ionophore - salinomycin, Anti-cancer Agents Med. Chem. 15 (2015) 575-591.

[54] S. Zhou, F. Wang, E.T. Wong, E. Fonkem, T.-C. Hsieh, J.M. Wu, E. Wu, Salinomycin: A novel anticancer agent with known anti-coccidial activities, Curr. Med. Chem. 20 (2013) 4095-4101.

[55] C.P. Taborda, L.R. Travassos, Peptide vaccine against paracoccidioidomycosis, Methods Mol. Biol. 1625 (2017) 113-128.

[56] D. Steverding, Sleeping sickness and nagana disease caused by Trypanosoma brucei, in: C. Marcondes (Ed.) Arthropod Borne Diseases, Springer, Cham, 2017.

[57] J.R. Franco, P.P. Simarro, A. Diarra, J.G. Jannin, Epidemiology of human African trypanosomiasis, Clin. Epidemiol. 6 (2014) 257-275.

[58] A. Stich, P.M. Abel, S. Krishna, Human African trypanosomiasis, BMJ 325 (2002) 203-206.

[59] G. Cecchi, R.C. Mattioli, J. Slingenbergh, S. De La Rocque, Land cover and tsetse fly distributions in sub-Saharan Africa, Med. Vet. Entomol. 22 (2008) 364-373.

[60] D. Malvy, F. Chappuis, Sleeping sickness, Clin. Microbiol. Infect. 17 (2011) 986-995.

[61] D. Steverding, The history of African trypanosomiasis, Parasit. Vectors 1 (2008) 3.

[62] World Health Organization - Human African trypanosomiasis, [on-line access: 2018-10-09]. http://www.who.int/trypanosomiasis_african/en/

[63] L. MacLean, H. Reiber, P.G.E. Kennedy, J.M. Sternberg, Stage progression and neurological symptoms in Trypanosoma brucei rhodesiense sleeping sickness: Role of the CNS inflammatory response, PLoS Negl. Trop. Dis. 6 (2012) e1857. 
[64] Y. Dauvilliers, S. Bisser, F. Chapotot, G. Vatunga, R. Cespuglio, T. Josenando, A. Buguet, Hypocretin and human African trypanosomiasis, Sleep 32 (2008) 348-354.

[65] D. Steverding, A. Huczyński, Trypanosoma brucei: trypanocidal and cell swelling activities of lasalocid acid, Parasitol. Res. 116 (2017) 3229-3233.

[66] D. Steverding, M. Antoszczak, A. Huczyński, In vitro activity of salinomycin and monensin derivatives against Trypanosoma brucei, Parasit. Vectors 9 (2016) 409.

[67] D. Steverding, D.W. Sexton, Trypanocidal activity of salinomycin is due to sodium influx followed by cell swelling, Parasit. Vectors 6 (2013) 78.

[68] B. Alemayehu, M. Alemayehu, Leishmaniasis: A review on parasite, vector and reservoir host, Health Sci. J. 11 (2017) 519.

[69] D. Steverding, The history of leishmaniasis, Parasit. Vectors 10 (2017) 82.

[70] A. Dostálová, P. Volf, Leishmania development in sand flies: Parasite-vector interactions overview, Parasit. Vectors 5 (2012) 276.

[71] M. Hide, B. Bucheton, S. Kamhawi, R. Bras-Gonçalves, S. Sundar, J.-L. Lemesre, A.-L. Bañuls, Understanding human leishmaniasis: The need for an integrated approach, in: M.Tibayrenc (Ed.), Encyclopedia of infectious diseases: Modern methodologies, John Wiley \& Sons, Inc., 2007.

[72] World Health Organization - Leishmaniasis, [on-line access: 2018-10-09]. http://www.who.int/leishmaniasis/en/

[73] C. Bern, J.H. Maguire, J. Alvar, Complexities of assessing the disease burden attributable to leishmaniasis, PLoS Negl. Trop. Dis. 2 (2008) e313.

[74] A. Oryan, M. Akbari, Worldwide risk factors in leishmaniasis, Asian Pac. J. Trop. Med. 9 (2016) 925932.

[75] E. Torres-Guerrero, M.R. Quintanilla-Cedillo, J. Ruiz-Esmenjaud, R. Arenasa, Leishmaniasis: A review, F1000Res $6(2017) 750$.

[76] N. Aronson, B.L. Herwaldt, M. Libman, R. Pearson, R. Lopez-Velez, P. Weina, E.M. Carvalho, M. Ephros, S. Jeronimo, A. Magill, Diagnosis and treatment of leishmaniasis: Clinical practice guidelines by the Infectious Diseases Society of America (IDSA) and the American Society of Tropical Medicine and Hygiene (ASTMH), Clin. Infect. Dis. 63 (2016) e202-e264.

[77] J. van Griensven, E. Carrillo, R. López-Vélez, L. Lynen, J. Moreno, Leishmaniasis in immunosuppressed individuals, Clin. Microbiol. Infect. 20 (2014) 286-299. 
[78] Y. Osorio, B.L. Travi, A.R. Renslo, A.G. Peniche, P.C. Melby, Identification of small molecule lead compounds for visceral leishmaniasis using a novel ex vivo splenic explant model system, PLoS Negl. Trop. Dis. 5 (2011) e962.

[79] A.G. Peniche, Y. Osorio, A.R. Renslo, D.E. Frantz, P.C. Melby, B.L. Travia, Development of an ex vivo lymph node explant model for identification of novel molecules active against Leishmania major, Antimicrob. Agents Chemother. 58 (2014) 78-87.

[80] J.R. Luque-Ortega, J.M. Saugar, C. Chiva, D. Andreu, L. Rivas, Identification of new leishmanicidal peptide lead structures by automated real-time monitoring of changes in intracellular ATP, Biochem. J. 375 (2003) 221-230.

[81] C. Gumila, M.L. Ancelin, G. Jeminet, A.M. Delort, G. Miquel, H.J. Vial, Differential in vitro activities of ionophore compounds against Plasmodium falciparum and mammalian cells, Antimicrob. Agents Chemother. 40 (1996) 602-608.

[82] C.C. Campbell, Malaria: An emerging and re-emerging global plague, FEMS Immunol. Med. Mic. 18 (1997) 325-331.

[83] World Health Organization - Malaria, [on-line access: 2018-10-09]. http://www.who.int/malaria/en/

[84] B. Hanboonkunupakarn, N.J. White, The threat of antimalarial drug resistance, Trop. Dis. Travel Med. Vaccines 2 (2016) 10.

[85] N.J. White, Antimalarial drug resistance, J. Clin. Invest. 113 (2004) 1084-1092.

[86] K. Otoguro, A. Kohana, C. Manabe, A. Ishiyama, H. Ui, K. Shiomi, H. Yamada, S. Omura, Potent antimalarial activities of polyether antibiotic, X-206, J. Antibiot. 54 (2001) 658-63.

[87] J. Adovelande, J. Schrevel, Carboxylic ionophores in malaria chemotherapy: The effects of monensin and nigericin on Plasmodium falciparum in vitro and Plasmodium vinckei petteri in vivo, Life Sci. 59 (1996) 309-315.

[88] R. Leitao, A. Rodriguez, Inhibition of Plasmodium sporozoites infection by targeting the host cell, Exp. Parasitol. 126 (2010) 273-277.

[89] C. Gumila, M.L. Ancelin, A.M. Delort, G. Jeminet, H.J. Vial, Characterization of the potent in vitro and in vivo antimalarial activities of ionophore compounds, Antimicrob. Agets Chemother. 41 (1997) 523529.

[90] S. D’Alessandro, Y. Corbett, D.P. Ilboudo, P. Misiano, N. Dahiya, S.M. Abay, A. Habluetzel, R. Grande, M.R. Gismondo, K.J. Dechering, K.M.J. Koolen, R.W. Sauerwein, D. Taramelli, N. Basilico, 
S. Parapini, Salinomycin and other ionophores as a new class of antimalarial drugs with transmissionblocking activity, Antimicrob. Agents Chemother. 59 (2015) 5135-5144.

[91] J.N. Burrows, R.H. van Huijsduijnen, J.J. Möhrle, C. Oeuvray, T.N. Wells, Designing the next generation of medicines for malaria control and eradication, Malar. J. 12 (2013) 187.

[92] M.I. Maron, C.T. Magle, B. Czesny, B.A. Turturice, R. Huang, W. Zheng, A.B. Vaidya, K.C. Williamson, Maduramicin rapidly eliminates malaria parasites and potentiates the gametocytocidal activity of the pyrazoleamide PA21A050, Antimicrob. Agents Chemother. 60 (2016) 1492-1499.

[93] K. Otoguro, I. Aki, H. Ui, M. Kobayashi, C. Manabe, G. Yan, Y. Takahashi, H. Tanaka, H. Yamada, S. Omura, In vitro and in vivo antimalarial activities of the monoglycoside polyether antibiotic, K-41 against drug resistant strains of Plasmodia, J. Antibiot. 55 (2002) 832-834.

[94] V. Rajendran, S. Rohra, M. Raza, G.M. Hasan, S. Dutt, P.C. Ghosh, Stearylamine liposomal delivery of monensin in combination with free artemisinin eliminates blood stages of Plasmodium falciparum in culture and P. berghei infection in murine malaria, Antimicrob. Agents Chemother. 60 (2016) 13041318.

[95] M. Raza, H. Bharti, A. Singal, A. Nag, P.C. Ghosh, Long circulatory liposomal maduramicin inhibits the growth of Plasmodium falciparum blood stages in culture and cures murine models of experimental malaria, Nanoscale 10 (2018) 13773-13791.

[96] V. Rajendran, M. Pachauri, P.C. Ghosh, Combinatorial effects of monensin in liposome formulations with antimalarial drugs against blood stages of Plasmodium falciparum in culture and P. berghei infection, Curr. Drug Ther. 13 (2018) 74-82.

[97] R. Surolia, M. Pachauri, P.C. Ghosh, Preparation and characterization of monensin loaded PLGA nanoparticles: In vitro anti-malarial activity against Plasmodium falciparum, J. Biomed. Nanotechnol. 8 (2012) 172-81.

[98] M. Kawada, S. Sumi, K. Umezawa, S. Inouye, T. Sawa, H. Seto, Circumvention of multidrug resistance in human carcinoma KB cells by polyether antibiotics, J. Antibiot. 45 (1992) 556-562.

[99] S. Das, S. Bhatanagar, J.M. Morrisey, T.M. Daly, J.M. Burns Jr., I. Coppens, A.B. Vaidya, Na ${ }^{+}$influx induced by new antimalarials causes rapid alterations in the cholesterol content and morphology of Plasmodium falciparum, PLoS Pathog. 12 (2016) e1005647. 
[100] J.W. Westley, C.M. Liu, R.H. Evans, L.H. Sello, N. Troupe, T. Hermann, Preparation, properties and biological activity of natural and semisynthetic urethanes of monensin, J. Antibiot. 36 (1983) $1195-$ 1200

[101] R. Tanaka, A. Nagatsu, H. Mizukami, Y. Ogihara, J. Sakakibara, Studies on chemical modification of monensin. IX. Synthesis of 26-substituted monensins and their $\mathrm{Na}^{+}$ion transport activity, Chem. Pharm. Bull. 49 (2001) 711-715.

[102] M. Rochdi, A.M. Delort, J. Guyot, M. Sancelme, S. Gibot, J.G. Gourcy, G. Dauphin, C. Gumila, H. Vial, G. Jeminet, Ionophore properties of monensin derivatives studied on human erythrocytes by ${ }^{23} \mathrm{Na}$ $\mathrm{NMR}$ and $\mathrm{K}^{+}$and $\mathrm{H}^{+}$potentiometry: Relationship with antimicrobial and antimalarial activities, J. Med. Chem. 39 (1996) 588-595.

[103] M. Mehrpour, R. Rodriguez, A. Hienzsch, M. Trang, A. Hamai, Nitrogen-containing analogs of salinomycin, synthesis and use against cancer stem cells and malaria, European Patent Application No. EP3191493. (data not shown)

[104] M. Martinot, M.M. Zadeh, Y. Hansmann, I. Grawey, D. Christmann, S. Aguillon, M. Jouglin, A. Chauvin, D. De Briel, Babesiosis in immunocompetent patients, Europe, Emerg. Infect. Dis. 17 (2011) 114-116.

[105] M.J. Homer, I. Aguilar-Delfin, S.R. Telford III, P.J. Krause, D.H. Persing, Babesiosis, Clin. Microbiol. Rev. 13 (2000) 451-469.

[106] S. Zanet, A. Trisciuoglio, E. Bottero, I.G. Fernández de Mera, C. Gortazar, M.G. Corpignano, E. Ferroglio, Piroplasmosis in wildlife: Babesia and Theileria affecting free-ranging ungulates and carnivores in the Italian Alps, Parasit. Vectors 7 (2014) 70.

[107] D.A. Leiby, Transfusion-transmitted Babesia spp.: Bull's-eye on Babesia microti, Clin. Microbiol. Rev. 24 (2011) 14-28.

[108] E. Vannier, B.E. Gewurz, P.J. Krause, Human babesiosis, Infect. Dis. Clin. North Am. 22 (2008) 469.

[109] E.G. Vannier, M.A. Diuk-Wasser, C. Ben Mamoun, P.J. Krause, Babesiosis, Infect. Dis. Clin. North Am. 29 (2015) 357-370.

[110] L.F. Westblade, M.S. Simon, B.A. Mathison, L.A. Kirkman, Babesia microti: From mice to ticks to an increasing number of highly susceptible humans, J. Clin. Microbiol. 55 (2017) 2903-2912.

[111] National Organization for Rare Disorders - Babesiosis [on-line access: 2018-10-09]. https://rarediseases.org/rare-diseases/babesiosis/ 
[112] Centers for Disease Control and Prevention - Babesiosis [on-line access: 2018-10-09]. https://www.cdc.gov/parasites/babesiosis/

[113] M. Yamasaki, K. Nakamura, N. Tamura, S.-J. Hwang, M. Yoshikawa, N. Sasaki, H. Ohta, O. Yamato, Y. Maede, M. Takiguchi, Effects and mechanisms of action of ionophorous antibiotics valinomycin and salinomycin-Na on Babesia gibsoni in vitro, J. Parasitol. 95 (2009) 1532-1538.

[114] S.K. Halonen, L.M. Weiss, Toxoplasmosis, Handb. Clin. Neurol. 114 (2013) 125-145.

[115] F. Robert-Gangneux, M.-L. Dardé, Epidemiology of and diagnostic strategies for toxoplasmosis, Clin. Microbiol. Rev. 25 (2012) 264-296.

[116] S. Singh, Congenital toxoplasmosis: Clinical features, outcomes, treatment, and prevention, Trop. Parasitol. 6 (2016) 113-122.

[117] D.S. Fox, Toxoplasmosis, in: L.C. Garfunkel, J.M. Kaczorowski, C. Christy (Eds.), Pediatric clinical advisor (Second Edition). Instant diagnosis and treatment, Elsevier 2007.

[118] Centers for Disease Control and Prevention - Toxoplasmosis [on-line access: 2018-10-09]. https://www.cdc.gov/parasites/toxoplasmosis/

[119] P.R. Torgerson, P. Mastroiacovo, The global burden of congenital toxoplasmosis: A systematic review, Bull. World Health Organ. 91 (2013) 501-508.

[120] S.Y. Wong, J.S. Remington, Biology of Toxoplasma gondii, Aids 7 (1993) 299-316.

[121] T. Carrada-Bravo, Toxoplasmosis. A public health problem. Advances and perspectives, Bol. Med. Hosp. Infant. Mex. 40 (1983) 353-362.

[122] S. Couzinet, J.F. Dubremetz, D. Buzoni-Gatel, G. Jeminet, G. Prensier, In vitro activity of the polyether ionophorous antibiotic monensin against the cyst form of Toxoplasma gondii, Parasitol. 12 (2000) 359365.

[123] S. Couzinet, J.F. Dubremetz, L. David, G. Prensier, Toxoplasma gondii: Activity of the polyether ionophorous antibiotic nigericin on tachyzoites in cell culture, Exp. Parasitol. 78 (1994) 341-351.

[124] J.P. Dubey, Toxoplasmosis in sheep - The last 20 years, Vet. Parasitol. 163 (2009) 1-14.

[125] C.A. Kirkbride, J.P. Dubey, M.C. Libal, Effect of feeding lasalocid to pregnant ewes experimentally infected with Toxoplasma gondii, Vet. Parasitol. 44 (1992) 299-303.

[126] D. Buxton, D.A. Blewett, A.J. Trees, C. McColgan, J. Finlayson, Further studies in the use of monensin in the control of experimental ovine toxoplasmosis, J. Comp. Pathol. 98 (1988) 225-236. 
[127] J. Huskinson-Mark, F.G. Araujo, J.S. Remington, Evaluation of the effect of drugs on the cyst form of Toxoplasma gondii, J. Infect. Dis. 164 (1991) 170-171.

[128] M.D. Lavine, G. Arrizabalaga, The antibiotic monensin causes cell cycle disruption of Toxoplasma gondii mediated through the DNA repair enzyme TgMSH-1, Antimicrob. Agents Chemother. 55 (2011) $745-755$.

[129] J.M. Varberg, K.A. LaFavers, G. Arrizabalaga, W.J. Sullivan Jr., Characterization of Plasmodium Atg3 Atg8 interaction inhibitors identifies novel alternative mechanisms of action in Toxoplasma gondii, Antimicrob. Agents Chemother. 62 (2018) e01489-17.

[130] M.D. Lavine, G. Arrizabalaga, Analysis of monensin sensitivity in Toxoplasma gondii reveals autophagy as a mechanism for drug induced death, PLoS ONE 7 (2012) e42107.

[131] S.L. Donahoe, S.A. Lindsay, M. Krockenberger, D. Phalen, J. Šlapeta, A review of neosporosis and pathologic findings of Neospora caninum infection in wildlife, Int. J. Parasitol. Parasites Wildl. 4 (2015) 216-238.

[132] A. Hemphill, B. Gottstein, A European perspective on Neospora caninum, Int. J. Parasitol. 30 (2000) 877-924.

[133] L.-J. Jia, S.-F. Zhang, M.-M. Liu, N.-C. Qian, H.-P. Guo, Isolation, identification, and pathogenicity of Neospora caninum China Yanbian strain, Iran. J. Parasitol. 9 (2014) 394-401.

[134] E.A. Innes, The host-parasite relationship in pregnant cattle infected with Neospora caninum, Parasitol. 134 (2007) 1903-1910.

[135] T. Monney, K. Debache, A. Hemphill, Vaccines against a major cause of abortion in cattle, Neospora caninum infection, Animals (Basel) 1 (2011) 306-325.

[136] J.P. Dubey, D. Buxton, W. Wouda, Pathogenesis of bovine neosporosis, J. Comp. Pathol. 134 (2006) $267-289$.

[137] J.P.A. Haddad, I.R. Dohoo, J.A. VanLeewen, A review of Neospora caninum in dairy and beef cattle a Canadian perspective, Can. Vet. J. 46 (2005) 230-243.

[138] D.S. Lindsay, N.S. Rippey, R.A. Cole, L.C. Parsons, J.P. Dubey, R.R. Tidwell, B.L. Blagburn, Examination of the activities of 43 chemotherapeutic agents against Neospora caninum tachyzoites in cultured cells, Am. J. Vet. Res. 55 (1994) 976-981.

[139] S. Kadykalo, T. Roberts, M. Thompson, J. Wilson, M. Lang, O. Espeisse, The value of anticoccidials for sustainable global poultry production, Int. J. Antimicrob. Agents, 51 (2018) 304-310. 
[140] A.K. Bera, D. Bhattacharya, D. Pan, A. Dhara, S. Kumar, S.K. Das, Evaluation of economic losses due to coccidiosis in poultry industry in India, Agric. Econ. Res. Rev. 23 (2010) 91-96.

[141] H.W. Peek, W.J. Landman, Coccidiosis in poultry: Anticoccidial products, vaccines and other prevention strategies, Vet. Q. 31 (2011) 143-161.

[142] R.E. Quiroz-Castañeda, E. Dantán-González, Control of avian coccidiosis: Future and present natural alternatives, BioMed. Res. Int. 2015 (2015) 430610.

[143] O. Dezfoulian, M.J. Gharagozlou, S. Rahbari, R. Samani, Coccidiosis due to various species of Eimeria in the stunted and diarrheic native turkey poults: Pathology and morphological characterization of oocysts, Arch. Razi Inst. 65 (2010) 15-19.

[144] J.F. Stephens, Some physiological effects of coccidiosis caused by Eimeria necatrix in the chicken, J. Parasitol. 51 (1965) 331-335.

[145] H.D. Chapman, T.K. Jeffers, R.B. Williams, Forty years of monensin for the control of coccidiosis in poultry, Poult. Sci. 89 (2010) 1788-1801.

[146] S.L.A. Cerruti Sola, A. Agostini, M. Castagnaro, Efficacy of maduramicin against turkey coccidiosis in battery: A clinical and pathological study, Schweiz. Arch. Tierheildkd. 138 (1996) 201-206.

[147] D.P. Conway, J.K. Johnson, V. Guyonnet, P.L. Long, C.D. Smothers, Efficacy of semduramicin and salinomycin against different stages of Eimeria tenella and E. acervulina in the chicken, Vet. Parasitol. 45 (1993) 215-229.

[148] C.K. Smith 2nd, R.G. Strout, Eimeria tenella: Effect of narasin, a polyether antibiotic on the ultrastructure of intracellular sporozoites, Exp. Parasitol. 50 (1980) 426-436.

[149] J.P. Dirlam, A.M. Belton, J. Bordner, W.P. Cullen, L.H. Huang, Y. Kojima, H. Maeda, S. Nishiyama, J.R. Oscarson, A.P. Ricketts, T. Sakakibara, J. Tone, K. Tsukuda, M. Yamada, CP-82,009, a potent polyether anticoccidial related to septamycin and produced by Actinomadura, J. Antibiot. 45 (1992) $331-340$.

[150] Y. Takahashi, H. Nakamura, R. Ogata, N. Matsuda, M. Hamada, H. Naganawa, T. Takita, K. Sato, T. Takeuchi, Kijimicin, a polyether antibiotic, J. Antibiot. 43 (1990) 441-443.

[151] J.P.Dirlam, A.M. Belton, J. Bordner, W.P. Cullen, L.H. Huang, Y. Kojima, H. Maeda, H. Nishida, S. Nishiyama, J.R. Oscarson, A.P. Ricketts, T. Sakakibara, J. Tone, K. Tsukuda, CP-84,657, a potent polyether anticoccidial related to portmicin and produced by Actinomadura sp., J. Antibiot. 43 (1990) $668-679$. 
[152] S.D. Folz, B.L. Lee, L.H. Nowakowski, G.A. Conder, Anticoccidial evaluation of halofuginone, lasalocid, maduramicin, monensin and salinomycin, Vet. Parasitol. 28 (1988) 1-9.

[153] C.M. Liu, T.E. Hermann, A. Downey, B.T. Prosser, E. Schildknecht, H.J. Palleroni, J.W. Westley, P.A. Miller, Discovery, fermentation, biological as well as ionophore properties and taxonomy of the producing culture, J. Antibiot. 36 (1983) 343-350.

[154] Y. Myiazaki, M. Shibuya, H. Sugawara, O. Kawaguchi, C. Hirose, J. Nagatsu, S. Esumi, Salinomycin, a new polyether antibiotic, J. Antibiot. 27 (1974) 814-821.

[155] A.P. Ricketts, E.A. Glazer, T.T. Migaki, J.A. Olson, Anticoccidial efficacy of semduramicin in battery studies with laboratory isolates of coccidian, Poult. Sci. 71 (1992) 98-103.

[156] R.W. Gerhold, A.L. Fuller, L. Lollis, C. Parr, L.R. McDougald, The efficacy of anticoccidial products against Eimeria spp. in northern bobwhites, Avian Dis. 55 (2011) 59-64.

[157] R.W. Gerhold, A.L. Fuller, L.R. McDougald, Coccidiosis in the chukar partridge (Alectoris chukar): A survey of coccidiosis outbreaks and a test of anticoccidial drugs against Eimeria kofoidi, Avian Dis. 60 (2016) 752-757.

[158] K.M.S. Islam, U. Klein, D.G.S. Burch, The activity and compatibility of the antibiotic tiamulin with other drugs in poultry medicine - A review, Poult. Sci. 88 (2009) 2353-2359.

[159] E. del Cacho, M. Gallego, C. Sánchez-Acedo, H.S. Lillehoj, Expression of flotillin-1 on Eimeria tenella sporozoites and its role in host cell invasion, J. Parasitol. 93 (2007) 328-332.

[160] C.K.I.I. Smith, R.G. Strout, Eimeria tenella: Accumulation and retention of anticoccidial ionophores by extracellular sporozoites, Exp. Parasitol. 48 (1979) 325-330.

[161] A.L. Donoho, Biochemical studies on the fate of monensin in animals and in the environment, J. Anim. Sci. 58 (1984) 1528-1539.

[162] R.F. Shumard, M.E. Callender, Monensin, a new biologically active compound. VI. Anticoccidial activity, Antimicrob. Agents Chemother. 7 (1967) 369-377.

[163] J. Delaveau, E. Vialle, M. Lemaire, S. Pellet-Rostaing, B. Andrioletti. Novel monensin derivatives for the treatment and prevention of protozoal infections, EP2640728B1, Date of publication: 07.09.2016

[164] P. Hammann, W. Raether, L. Vertesy, Anticoccidial activity of salinomycin derivatives, J. Antibiot. (Tokyo). 46 (1993) 523-525.

[165] Centers for Disease Control and Prevention - Cryptosporidiosis [on-line access: 2018-10-09]. https://www.cdc.gov/parasites/crypto/ 
[166] G.J. Leitcha, Q. Heb, Cryptosporidiosis - an overview, J. Biomed. Res. 25 (2011) 1-16.

[167] N. Pumipuntu, S. Piratae, Cryptosporidiosis: A zoonotic disease concern, Vet. World 11 (2018) 681686.

[168] A. Zahedi, A. Paparini, F. Jian, I. Robertson, U. Ryan, Public health significance of zoonotic Cryptosporidium species in wildlife: Critical insights into better drinking water management, Int. J. Parasitol. Parasites Wildl. 5 (2016) 88-109.

[169] L. Xiao, Y. Feng, Zoonotic cryptosporidiosis, FEMS Immunol. Med. Microbiol. 52 (2008) 309-323.

[170] A. Zahedi, P. Monis, S. Aucote, B. King, A. Paparini, F. Jian, R. Yang, C. Oskam, A. Ball, I. Robertson, U. Ryan, Zoonotic Cryptosporidium species in animals inhabiting Sydney water catchments, PLoS One 11 (2016) e0168169.

[171] E. Pozio, Foodborne and waterborne parasites, Acta Microbiol. Pol. 52 (2003) 83-96.

[172] Y.A. Lim, M. Rohela, B.L. Sim, I. Jamaiah, M. Nurbayah, Prevalence of cryptosporidiosis in HIVinfected patients in Kajang Hospital, Selangor, Southeast Asian J. Trop. Med. Public Health 36 (2005) $30-33$

[173] H. Fujikawa, H. Miyakawa, K. Iguchi, M. Nishizawa, K. Moro, K. Nagai, M. Ishibashi, Intestinal cryptosporidiosis as an initial manifestation in a previously healthy Japanese patient with AIDS, J. Gastroenterol. 37 (2002) 840-843.

[174] J. Euzeby, The epidemiology of human cryptosporidiosis, Bull. Acad. Natl. Med. 186 (2002) 837-850.

[175] T.P. Flanigan, Human immunodeficiency virus infection and cryptosporidiosis: Protective immune responses, Am. J. Trop. Med. Hyg. 50 (1994) 29-35.

[176] J. Slapeta, Cryptosporidiosis and Cryptosporidium species in animals and humans: A thirty colour rainbow? Int. J. Parasitol. 43 (2013) 957-970.

[177] M.S. Love, F.C. Beasley, R.S. Jumani, T.M. Wright, A.K. Chatterjee, C.D. Huston, P.G. Schultz, C.W. McNamara, A high-throughput phenotypic screen identifies clofazimine as a potential treatment for cryptosporidiosis, PLoS Negl. Trop. Dis. 11 (2017) e0005373.

[178] K. Teichmann, M. Kuliberda, G. Schatzmayr, F. Hadacek, A. Joachim, In vitro determination of anticryptosporidial activity of phytogenic extracts and compounds, Parasitol. Res. 111 (2012) 231-240.

[179] M. Shahiduzzaman, V. Dyachenko, A. Obwaller, S. Unglaube, A. Daugschies, Combination of cell culture and quantitative PCR for screening of drugs against Cryptosporidium parvum, Vet. Parasitol. 162 (2009) 271-277. 
[180] P.R. Hunter, G. Nichols, Epidemiology and clinical features of Cryptosporidium infection in immunocompromised patients, Clin. Microbiol. Rev. 15 (2002) 145-154.

[181] X. You, R.F. Schinazi, M.J. Arrowood, M. Lejkowski, A.S. Juodawlkis, J.R. Mead, In-vitro activities of paromomycin and lasalocid evaluated in combination against Cryptosporidium parvum, J. Antimicrob. Chemother. 41 (1998) 293-296.

[182] K.M. Woods, M.V. Nesterenko, S.J. Upton, Efficacy of 101 antimicrobials and other agents on the development of Cryptosporidium parvum in vitro, Ann. Trop. Med. Parasitol. 90 (1996) 603-615.

[183] J.R. Mead, X. You, J.E. Pharr, Y. Belenkaya, M.J. Arrowood, M.T. Fallon, R.F. Schinazi, Evaluation of maduramicin and alborixin in a SCID mouse model of chronic cryptosporidiosis, Antimicrob. Agents Chemother. 39 (1995) 854-858.

[184] B.L. Blagburn, C.A. Sundermann, D.S. Lindsay, J.E. Hall, R.R. Tidwell, Inhibition of Cryptosporidium parvum in neonatal Hsd:(ICR)BR Swiss miceby polyether ionophores and aromatic amidines, Antimicrob. Agents Chemother. 35 (1991) 1520-1523.

[185] V. Mcdonald, R. Stables, D.C. Warhurst, M.R. Barer, D.A. Blewett, H.D. Chapman, G.M. Connolly, P.L. Chiodini, K.P. McAdam, In vitro cultivation of Cryptosporidium parvum and screening for anticryptosporidial drugs, Antimicrob. Agents Chemother. 34 (1990) 1498-1500.

[186] S.R. Tzipori, I. Campbell, K.W. Angus, The therapeutic effect of 16 antimicrobial agents on Cryptosporidium infection in mice, Aust. J. Exp. Biol. Med. Sci. 60 (1982) 187-190.

[187] M. Fathi, J. Sadraei, F. Ghaffarifar, Effects of two anticoccidial drugs, Monensin, Toltrazuril and the mixture of them on Cryptosporidium parvum in vitro, Jundishapur J. Microbiol. 4 (2011) 71-74.

[188] J.-F. Rossignol, Cryptosporidium and Giardia: Treatment options and prospects for new drugs, Exp. Parasitol. 124 (2010) 45-53.

[189] E.M. Zardi, A. Picardi, A. Afeltra, Treatment of cryptosporidiosis in immunocompromised hosts, Chemother. 51 (2005) 193-196.

[190] F. Murakoshi, M. Takeuchi, A. Inomata, T. Horimoto, M. Ito, Y. Suzuki, K. Kato, Administration of lasalocid-NA is preventive against cryptosporidiosis of newborn calves, Vet. Rec. 11 (2014) 353.

[191] D. Lemeteil, F. Roussel, L. Favennec, J.J. Ballet, P. Brasseur, Assessment of candidate anticryptosporidial agents in an immunosuppressed rat model, J. Infect. Dis. 167 (1993) 766-769.

[192] M.A. Saeed, M.H. Rashid, J. Vaughan, A. Jabbar, Sarcocystosis in South American camelids: The state of play revisited, Parasit. Vectors 11 (2018) 146. 
[193] D.S. Lindsay, S.M. Mitchell, J. Yang, J.P. Dubey, R.M. Gogal Jr., S.G. Witonsky, Penetration of equine leukocytes by merozoites of Sarcocystis neurona, Vet. Parasitol. 138 (2006) 371-376.

[194] R. Fayer, D.H. Esposito, J.P. Dubey, Human infections with Sarcocystis species, Clin. Microbiol. Rev. 28 (2015) 295-311.

[195] J.N. Velásquez, C. Di Risio, C.B. Etchart, A.V. Chertcoff, N. Mendez, M.G. Cabrera, J.H. Labbé, S. Carnevale, Systemic sarcocystosis in a patient with acquired immune deficiency syndrome, Hum. Pathol. 39 (2008) 1263-1267.

[196] S. Bunyaratvej, P. Unpunyo, A. Pongtippan, The Sarcocystis-cyst containing beef and pork as the sources of natural intestinal sarcocystosis in Thai people, J. Med. Assoc. Thai. 90 (2007) 2128-2135.

[197] M.B. Chhabra, S. Samantaray, Sarcocystis and sarcocystosis in India: Status and emerging perspectives, J. Parasit. Dis. 37 (2013) 1-10.

[198] K. Srinivasa Rao, M. Hafeez, Efficacy of amprolium and maduramycin against sarcocystosis in experimentally infected pups, J. Parasitic. Dis. 26 (2002) 111-113.

[199] M.A. Saeed, M.H. Rashid, J. Vaughan, A. Jabbar, Sarcocystosis in South American camelids: The state of play revisited, Parasit. Vectors 11 (2018) 146.

[200] R.G. Leek, R. Fayer, Experimental Sarcocystis ovicanis infection in lambs: Salinomycin chemoprophylaxis and protective immunity, J. Parasitol. 69 (1983) 271-276.

[201] A. Kumar, P.S. Srivastava, S.R.P. Sinha SRP, Chemotherapy of experimental caprine sarcocystosis in goats and young dogs with salinomycin (Coxistac Pfizer), J. Vet. Parasitol. 2 (1988) 129-132.

[202] R.P.E. Yanong, Cryptocaryon irritans infections (marine white spot disease), [on-line access: 2018-1009]. http://edis.ifas.ufl.edu/pdffiles/FA/FA16400.pdf

[203] A. Colorni, P. Burgess, Cryptocaryon irritans Brown 1951, the cause of 'white spot disease' in marine fish: An update, Aqua. Sci. Conserv. 1 (1997) 217-238.

[204] T. Yoshinaga, H.W. Dickerson, Laboratory propagation of Cryptocaryon irritans on a saltwater-adapted Poecilia hybrid, the Black Molly, J. Aqua. Animal Health 6 (1994) 197-201.

[205] D.W. Bruno, B. Nowak, D.G. Elliott, Guide to the identification of fish protozoan and metazoan parasites in stained tissue sections, Dis. Aquat. Org. 70 (2006) 1-36.

[206] T. Yoshinaga, H.J. Im, S. Nishida, K. Ogawa, In vitro and in vivo efficacies of ionophores against Cryptocaryon irritans, Aquaculture 321 (2011) 167-172. 
[207] D.P. McManus, D.W. Dunne, M. Sacko, J. Utzinger, B.J. Vennervald, X.-N. Zhou, Schistosomiasis, Nat. Rev. Dis. Primers 4 (2018) 1.

[208] D.G. Colley, A.L. Bustinduy, W.E. Secor, C.H. King, Human schistosomiasis, Lancet 383 (2014) 22532264.

[209] A.G.P. Ross, T.N. Chau, M.T. Inobaya, R.M. Olveda, Y. Li, D.A. Harn, A new global strategy for the elimination of schistosomiasis, Int. J. Infect. Dis. 54 (2017) 130-137.

[210] D.U. Olveda, Y. Li, R.M. Olveda, A.K. Lam, T.N.P. Chau, D.A. Harn, G.M. Williams, D.J. Gray, A.G.P. Ross, Bilharzia: Pathology, diagnosis, management and control, Trop. Med. Surg. 1 (2013) 135.

[211] World Health Organization - Schistosomiasis, [on-line access: 2018-10-09]. https://www.who.int/schistosomiasis/en/

[212] M. Ciddio, L. Mari, S.H. Sokolow, G.A. De Leo, R. Casagrandi, M. Gatto, The spatial spread of schistosomiasis: A multidimensional network model applied to Saint-Louis region, Senegal, Adv. Water Resour. 108 (2017) 406-415.

[213] B. Gryseels, Schistosomiasis, Infect. Dis. Clin. N. Am. 26 (2012) 383-397.

[214] A.G. Ross, D. Vickers, G.R. Olds, S.M. Shah, D.P. McManus, Katayama syndrome, Lancet Infect. Dis. 7 (2007) 218-224.

[215] D.N.M. Osakunor, M.E.J. Woolhouse, F. Mutapi, Paediatric schistosomiasis: What we know and what we need to know, PLoS Negl. Trop. Dis. 12 (2018) e0006144.

[216] A.G.P. Ross, A.C. Sleigh, Y. Li, G.M. Davis, G.M. Williams, Z. Jiang, Z. Feng, D.P. McManus, Schistosomiasis in the People's Republic of China: Prospects and challenges for the 21st century, Clin. Microbiol. Rev. 14 (2001) 270-295.

[217] M.-H. Abdulla, D.S. Ruelas, B. Wolff, J. Snedecor, K.-C. Lim, F. Xu, A.R. Renslo, J. Williams, J.H. McKerrow, C.R. Caffrey, Drug discovery for schistosomiasis: Hit and lead compounds identified in a library of known drugs by medium-throughput phenotypic screening, PLoS Negl. Trop. Dis. 3 (2009) e478.

[218] S. Howe, D. Zöphel, H. Subbaraman, C. Unger, J. Held, T. Engleitner, W.H. Hoffmann, A. Kreidenweiss, Lactate as a novel quantitative measure of viability in Schistosoma mansoni drug sensitivity assays, Antimicrob. Agents Chemother. 59 (2015) 1193-119. 